University of Montana

ScholarWorks at University of Montana

8-2008

\title{
No Evidence for Trade-Offs: Centaurea Plants from America are Better Competitors and Defenders
}

\author{
Wendy M. Ridenour \\ Jorge M. Vivanco \\ Yulong Feng \\ Jun-Ichiro Horiuchi \\ Ragan M. Callaway \\ University of Montana - Missoula, Ray.Callaway@mso.umt.edu
}

Follow this and additional works at: https://scholarworks.umt.edu/biosci_pubs

Part of the Biology Commons

Let us know how access to this document benefits you.

\section{Recommended Citation}

Ridenour, Wendy M.; Vivanco, Jorge M.; Feng, Yulong; Horiuchi, Jun-Ichiro; and Callaway, Ragan M., "No Evidence for Trade-Offs: Centaurea Plants from America are Better Competitors and Defenders" (2008). Biological Sciences Faculty Publications. 225.

https://scholarworks.umt.edu/biosci_pubs/225

This Article is brought to you for free and open access by the Biological Sciences at ScholarWorks at University of Montana. It has been accepted for inclusion in Biological Sciences Faculty Publications by an authorized administrator of ScholarWorks at University of Montana. For more information, please contact scholarworks@mso.umt.edu. 


\title{
NO EVIDENCE FOR TRADE-OFFS: CENTAUREA PLANTS FROM AMERICA ARE BETTER COMPETITORS AND DEFENDERS
}

\author{
Wendy M. Ridenour, ${ }^{1,4}$ Jorge M. Vivanco, ${ }^{2}$ Yulong Feng, ${ }^{3}$ Jun-ichiro Horiuchi, ${ }^{2}$ and Ragan M. Callaway ${ }^{1}$ \\ ${ }^{1}$ Division of Biological Sciences, The University of Montana, Missoula, Montana 59812 USA \\ ${ }^{2}$ Department of Horticulture, Colorado State University, Fort Collins, Colorado 80523 USA \\ ${ }^{3}$ Xishuangbanna Tropical Botanical Garden, Chinese Academy of Sciences, Kunming 650223 Yunnan Province, China
}

\begin{abstract}
The natural enemies hypothesis has led to a number of ideas by which invaders might evolve superior competitive ability. In this context, we compared growth, reproduction, competitive effect, competitive response, and defense capabilities between invasive North American populations of Centaurea maculosa and populations in Europe, where the species is native. We found that Centaurea from North America were larger than plants from European populations. North American Centaurea also demonstrated stronger competitive effects and responses than European Centaurea. However, competitive superiority did not come at a cost to herbivore defense. North American plants were much better defended against generalist insect herbivores and slightly better defended against specialists. North Americans showed a stronger inhibitory effect on the consumers (resistance) and a better ability to regrow after attack by herbivores (tolerance). Better defense by North Americans corresponded with higher constitutive levels of a biochemical defense compound precursor, tougher leaves, and more leaf trichomes than Europeans. North American $F_{1}$ progeny of field collected lines retained the traits of larger size and greater leaf toughness suggesting that genetic differences, rather than maternal effects, may be the cause of intercontinental differences, but these sample sizes were small. Our results suggest that the evolution of increased competitive ability may not always be driven by physiological trade-offs between the allocation of energy or resources to growth or to defense. Instead, we hypothesize that Centaurea maculosa experiences strong directional selection on novel competitive and defense traits in its new range.
\end{abstract}

Key words: allelopathy; Centaurea maculosa; competition; defense; EICA, evolution of increased competitive ability; herbivory; invasion; novel weapons.

\section{INTRODUCTION}

One of ecology's most perplexing questions is why human introduction of some plant species to new regions results in large increases in their abundance and competitive effects. The "natural enemies" hypothesis posits that exotic invaders explode in abundance because they are no longer suppressed by the specialist herbivore consumers they evolved with (Maron and Vilà 2001). Janzen (1975) hypothesized that populations freed from herbivory may lose adaptations to resist or tolerate herbivory over time. This idea has led to a number of hypotheses for how the competitive ability of invaders might evolve. Blossey and Nötzold (1995) proposed that such a release from natural enemies and loss of defense capabilities would allow plants to reallocate energy and resources from "defensive weapons" to growth - the "evolution of increased competitive ability" (EICA) - and would therefore make these new genotypes more competitive than their predecessors in the native range. Bossdorf et al. (2004) hypothesized that

Manuscript received 20 November 2006; revised 6 December 2007; accepted 11 December 2007; final version received 3 January 2008. Corresponding Editor: P. Alpert.

${ }^{4}$ E-mail: wendy.ridenour@gmail.com if competition were less in the invaded range and competitive ability involves traits with a fitness cost, then selection might act against competitive ability: the "evolutionary reduced competitive ability" or ERCA hypothesis. Alternatively, if invaders have an "allelopathic advantage against resident species" (the AARS hypothesis, described later) then stronger allelopathic effects may be selected for in invaded ranges (Callaway and Ridenour 2004).

Studies have shown that exotic genotypes can be larger or more reproductive than the genotypes from which they appear to have originated (Schierenbeck et al. 1994), and some experiments have demonstrated one or both predictions of the EICA hypothesis (Siemann and Rogers 2001, 2003, Maron et al. 2004, Wolfe et al. 2004), whereas other studies of invasive plant species have not found evidence for changes in defense or growth (Vilá et al. 2003, Bossdorf et al. 2004). Bossdorf et al. (2005) suggested that comparisons of growth and defense characteristics among native and introduced populations are limited by focusing on defense and growth, and recommended that other characteristics be measured. For example, only two studies have explicitly and experimentally addressed competition (see Vilá and Weiner 2004). Leger and Rice (2003) found that individuals of Eschscholzia californica from the species' 
invasive range in Chile grew larger and produced more flowers than native individuals when released from competition from other plants. Bossdorf et al. (2004) measured competition between invasive and native genotypes of Alliaria petiolata, but did not measure competition with other species. However, no study has reported direct measurements of the competitive effects and competitive responses of an invasive plant comparing populations from the native and invaded range.

The "novel weapons" hypothesis posits that exotic invaders explode in abundance because invaders possess unique biochemicals that are more effective against evolutionarily naïve plants, microbes, and generalist herbivores than against those species that have evolved tolerance in their communities of origin (Rabotnov 1982, Callaway and Aschehoug 2000, Mallik and Pelliser 2000, Callaway and Ridenour 2004, Vivanco et al. 2004, Callaway et al. 2005, Cappuccino and Arnason 2006, Thorpe 2006, Callaway et al. 2008). If invaders possess competitive traits such as allelochemicals that provide greater competitive advantages in their new habitats than in their regions of origin, or "defensive weapons" such as unique defense compounds, then selection pressure for the traits conferring competitive advantages may be much greater for invasive genotypes than conspecific genotypes remaining at home: the AARS hypothesis (Callaway and Ridenour 2004). These evolutionary implications suggest that invasive genotypes may evolve superior competitive or defense ability without costs to other ecological functions.

There is evidence that Centaurea maculosa Lam. (spotted knapweed, Asteraceae, recently suggested to be C. stoebe micranthos L.), one of North America's most devastating European invaders, possesses biochemicals that may function in a way predicted by the novel weapons hypothesis (species classification information available online). ${ }^{5}$ Centaurea exudes the compound ( \pm )-catechin, a biochemical "offensive weapon," from its roots (Bais et al. 2003, Weir 2003, Blair et al. 2005), which inhibits the growth of neighboring competing plants in laboratory experiments (Bais et al. 2003, Weir et al. 2003, 2006, Callaway et al. 2005, Perry et al. 2005a, b, D'Abrosca et al. 2006; Simões et al., in press) and can be phytotoxic in soils within the range of naturally occurring concentrations (Thelen et al. 2005, Thorpe 2006; Inderjit et al., in press; Perry et al., in press; J. Pollock, unpublished data). However, other research indicates that natural soil concentrations rarely if ever reach phytotoxic levels (Blair et al. 2005, 2006). Importantly, $( \pm)$-catechin and Centaurea may be more allelopathic to North American species than congeneric European species (Bais et al. 2003, Thorpe 2006; W. He and R. M. Callaway, unpublished data). In addition to a potential novel offensive weapon, glandular trichomes covering the epidermal surfaces of $C$. maculosa produce

${ }^{5}\langle$ http://plants.usda.gov/java/profile?symbol=CESTM $\rangle$ cnicin, a biologically active sesquiterpene lactone which may function as a novel defensive weapon and appears to only occur in some Centaurea species (Olson and Kelsey 1997).

Because Centaurea maculosa is a strong invader (Lesica and Shelley 1996) and appears to be allelopathic, we compared the growth, reproduction, and competitive effect and response of invasive North American populations of Centaurea to populations from Europe, where the species is native. We also examined the effects of North American and European populations of Centaurea on specialist and generalist herbivores and the response of the plants to herbivory.

\section{Methods}

We conducted a series of comparative greenhouse experiments using North American and European populations of Centaurea. Abiotic conditions were controlled so that growing conditions were identical for plants from both regions, thus allowing us to test for genetic variation among North American and European populations and rule out phenotypic plasticity (Reznick and Ghalambor 2001). All experiments except a comparison of $( \pm)$-catechin exudation were conducted at the University of Montana (Missoula, Montana, USA) in two different greenhouses. Each individual experiment was conducted in a single greenhouse. In this section we describe the general growing conditions for these experiments. For both greenhouses temperatures were between $15^{\circ}$ and $30^{\circ} \mathrm{C}$, corresponding with natural early summer temperatures. Natural light in the greenhouses was supplemented by metal halide bulbs, and total photosynthetically active radiation (PAR) during the day remained above $1200 \mu \mathrm{mol} \cdot \mathrm{m}^{-2} \cdot \mathrm{s}^{-1}$. All plants were grown in $2.4-\mathrm{L}$ pots $(18 \mathrm{~cm}$ diameter and 22 cm depth), and with the exception of the soil comparison experiment we used a mixture of $20 \%$ local grassland soil (Missoula, Montana, USA; Haploxerolls and Argixerolls) and $80 \%$ 20/30 grit silica sand. These soils have a $\mathrm{pH}$ of 6.2 and contain approximately $7 \%$ organic matter. We chose this soil mix to be consistent with a number of previous experiments, to facilitate harvest of the fragile fine-root systems of $C$. maculosa, and to provide microbiota from the invaded range. Plants in our experiments were watered approximately every other day until the soil was saturated, and fertilized with 500 $\mathrm{mL}$ of Miracle-Gro at $0.34 \mathrm{~g} / \mathrm{L}$ every two to three weeks. Over the course of a 200-day experiment (a typical length) this provided approximately $225 \mathrm{mg}$ of total $\mathrm{N}$, $450 \mathrm{mg}$ of available $\mathrm{P}\left(\mathrm{P}_{2} \mathrm{O}_{5}\right)$, and $225 \mathrm{mg}$ of potash $\left(\mathrm{K}_{2} \mathrm{O}\right)$ to each pot. In all experiments, plants from different populations and regions were randomly spatially arranged on benches and rotated periodically. In all experiments in which two plants were in the same pot, they were planted so that the central stems were 10 $\mathrm{cm}$ apart. We conducted greenhouse rather than common garden experiments to avoid introducing novel European genotypes (via pollen and seeds) to North 
America. Consequently, our design does not take into account conditionality in the responses of North American and European populations, as demonstrated by Maron et al. (2004) for Hypericum perforatum grown in multiple common gardens in different parts of the world. We collected seeds from 22 European Centaurea populations and 23 North American Centaurea populations over the period of time we conducted these experiments, but the number of populations used in a single experiment ranged from 11 to 14 in the original growth and competition experiment to five and five in one of the herbivore experiments (Appendix A, Table 1). For each experiment populations were chosen randomly from the available pool; however the available pool of populations varied as seeds from new populations were acquired and as we ran out of seeds for some populations as experiments progressed. For each population (with the exception of three European populations, denoted in Appendix A, for which we did not know the collection protocol) we collected 300-3000 seeds from 30-100 parent plants. Seeds from a single population were mixed and selected randomly for each experiment.

\section{Statistical analysis}

We took the same two-step approach to analyzing data collected in different greenhouse experiments for plant biomass, flower head production, and most measurements of insect growth response and effect on plants. First, we used nested ANOVA to explore how trait variation differed among populations and between continents of population origin. We performed these tests using the PROC GLM module within SAS using Type III sum of squares (SAS version 9.1, SAS Institute, Cary, North Carolina, USA), where continent of population origin (Europe vs. North America) was treated as a fixed factor and population nested within continent was treated as a random factor. Second, we performed ANCOVA (in SPSS 11.5; SPSS, Chicago, Illinois, USA) on population means, using continent of population origin as a fixed factor and latitude as a covariate. Since preliminary analyses revealed no continent $\times$ latitude interaction for any trait, this term was not used in any further analyses. In a few cases we used other independent variables as covariates in the basic model described above, and these cases are described in the section relevant to the particular dependent variable tested.

There were a few cases in which there was no replication within populations (germination, competitive effects, and responses) or this replication was reduced to levels that precluded analysis of variation within populations. The statistical analyses of these cases are discussed in the specific methods sections below. Finally, transformation of most data was not required to meet ANOVA assumptions, but germination and all data for leaf number or proportional responses to herbivores were log-transformed.

\section{Germination, growth, fitness, and competitive ability}

To measure germination rates we planted Centaurea seeds from eight European populations and eight North American populations (chosen randomly from available populations, Table 1) in flats in the greenhouse on 8 May 2004. Germination was recorded over three weeks.

In a second experiment, we compared the growth, flower head number, and the competitive effects of North American and European Centaurea on two native grass species and the competitive response of North American and European Centaurea to native grasses. This experiment used 14 European populations and 11 North American populations chosen randomly from those available (Table 1). On 16 April 2004, Centaurea seeds from both regions were planted either alone or with Pseudoroegneria spicata Pursh., or Festuca idahoensis Elmer, two common native species in the Northern Rocky Mountains. For each Centaurea population from each continent, eight individuals were grown in pots with Pseudoroegneria, and eight individuals from each Centaurea population were grown in pots with Festuca. The biomass and flower head production of these Centaurea plants grown with native grasses was compared to that of eight other individual Centaurea plants from each of the same populations grown alone. Twenty individuals of Pseudoroegneria and Festuca were grown alone and the mean total biomass of these individuals was compared to the mean total biomass of the Pseudoroegneria and Festuca individuals grown with Centaurea to determine the competitive effect of the invader. At the end of the experiment, 27 October 2004, after 193 days, the total aboveground and belowground biomass of all Centaurea, Pseudoroegneria, and Festuca was harvested, dried at $100^{\circ} \mathrm{C}$ for three days, and weighed. Flower heads on all Centaurea plants were also counted at this time. Approximately $65 \%$ of Centaurea plants produced flower heads during the experiment, and only these plants were used for the analyses of flower heads.

Continental differences in biomass, flower head number, and photosynthesis were analyzed with the nested ANOVA procedure described above. However, continental differences in germination were tested with a single ANOVA (in SPSS 11.5) with seed age as a covariate (dates of collection differed), and population means as independent samples. To calculate competitive responses of Centaurea, the mean biomass of plants from a particular population grown in competition was calculated as a percentage of the biomass of plants from the same population grown alone. Similarly, the competitive effect of Centaurea was measured as the mean population effect on each of the two native grasses as a percentage of the biomass of the grasses attained when grown alone. Therefore, these measurements provide no replication at the population level and differences between continents were determined with a $t$ test on the population means from each continent (in SPSS 11.5). 


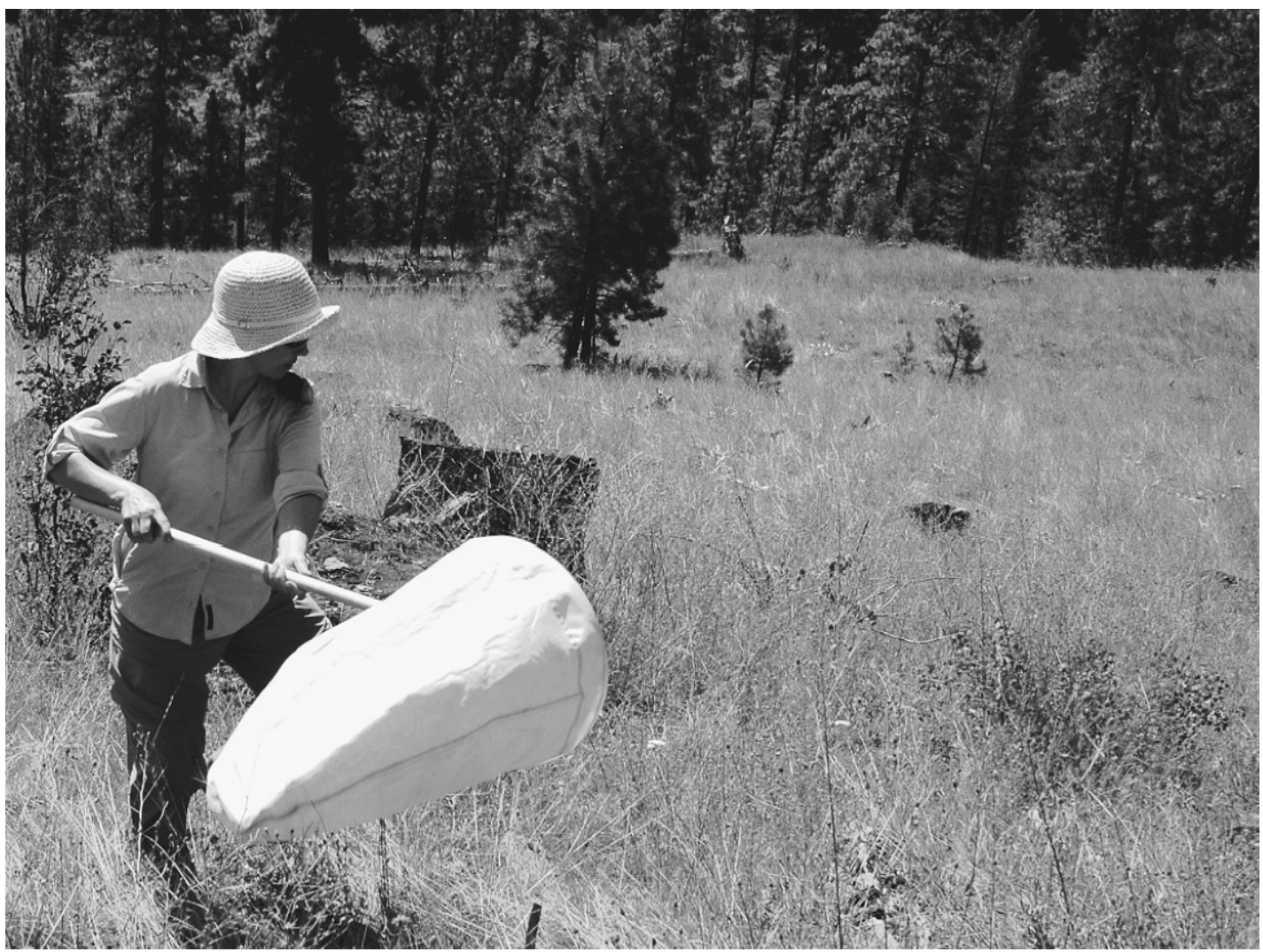

Plate 1. First author, Wendy Ridenour, collecting insects for laboratory experiments. Photo credit: Thomas Bassett.

European populations of C. maculosa can be either tetraploid or diploid (H. Müller-Schärer, personal communication), and we did not know the ploidy of our original populations. Therefore, in a later experiment we used seeds provided from H. Müller-Schärer and U. Trier at Fribourg University of eight tetraploid European populations and nine tetraploid North American populations not used in any other experiment described here. We grew these to maturity in the conditions described above for the other experiments for 170 days and then measured the diameter of the rosettes. Diameter was compared between regions and among populations statistically as described in Statistical analysis.

\section{Biogeographic differences in the effects of herbivores}

The following experiments were designed to compare the effects of North American and European populations of Centaurea on herbivore survival, growth, and maturation rates, and the response of North American and European populations of Centaurea to herbivory. We experimented with consumers that we have observed on Centaurea in the field in sites in western Montana (see Plate 1). These included two specialist root herbivores (both from Europe), one of which is also a shoot herbivore as an adult, and two generalist shoot herbivores (one naturalized in North America from Europe and one from North America).

The specialist herbivores Cyphocleonus achaetes (Fahraeus) (Insecta: Coleoptera: Curculionidae) and Agapeta zoegana (Linnaeus) (Insecta: Lepidoptera: Cochylidae) have been introduced as biocontrols for Centaurea and exist now in patchy populations throughout much of the weed's range. The European root boring weevil, $C$. achates, was first released in the United States in 1987. Cyphocleonus is a large, (approximately $20 \mathrm{~mm}$ long) brown-gray mottled, flightless weevil. Agapeta zoegana, a moth with root boring larvae from Europe, was first released in the United States in 1984. The larvae of Cyphocleonus and Agapeta overwinter in the roots of Centaurea and do substantial physical damage to the roots. Adult Cyphocleonus eat the leaves of Centaurea.

The naturalized generalist herbivore Trichoplusia $n i$ (Hubner) (Insecta: Lepidoptera: Noctuidae) is not used as a biocontrol for Centaurea; it occurs at very low abundances on the weed in natural communities ( $T$. Bassett and R. M. Callaway, unpublished data), but in experimental conditions larvae can do substantial damage to the leaves of Centaurea (Callaway et al. 1999). Larvae measure approximately $3-4 \mathrm{~cm}$ in length at maturity. The native generalist herbivore Melanoplus sanguinipes (Fabricius) (Insecta: Orthoptera: Acrididae), the lesser migratory grasshopper, is a broad generalist 
native to North America. Melanoplus has been periodically observed on Centaurea stems in the field (W. M. Ridenour, personal observation). We incorporated generalists into our experiments to test hypotheses suggested by Müller-Schärer et al. (2004). They proposed that the most important change in herbivory experienced by introduced plant species is a "shift in the composition in the enemy complex towards an assemblage dominated by generalists" and argued that this may result in differential selection on plant resistance traits.

Prior to introduction of insects in each experiment, all Centaurea plants were grown in the general conditions described above and were exposed to direct sunlight outside of the greenhouse in order to induce the production of flavonoids and other plant secondary metabolites.

Cyphocleonus achaetes.-On 21 April 2004, C. maculosa was started from seed for this herbivore treatment. On 15 August 2004, two adult Cyphocleonus weevils were introduced to each of 50 2.4-L pots, each pot containing one European and one North American Centaurea. As the plants matured during the experiment, the leaves of the two individuals consistently intermixed. We used eight populations of Centaurea from each continent for this experiment (Table 1), chosen randomly from the total set of available populations, and then each pair was established through random choices from the North American and European populations. For these 50 paired combinations, specific pairs of populations were only used once. Thus we did not use every possible combination of the 16 populations but pairs were evenly and objectively spread among possible combinations. Prior to adding Cyphocleonus, all Centaurea plant basal rosette diameters were measured in order to evaluate initial size as a potential determinant of herbivore choice. Adult Cyphocleonus were obtained from "Weedbusters" of Missoula, Montana. To keep the flightless Cyphocleonus weevils in their pots, circular cages were constructed of $30 \mathrm{~cm}$ tall sheets of clear mylar. The cages were open at the top, but the upper $3 \mathrm{~cm}$ of mylar was covered with a thin layer of petroleum jelly which was too slippery for Cyphocleonus to climb. Adult Cyphocleonus were allowed to selectively graze on their choice of European or North American Centaurea leaves and to lay their eggs in their choice of hosts until 21 October 2004, when all adult weevils were removed (183 days after planting, and 67 days after applying Cyphocleonus). At this time, all leaves of each Centaurea plant were counted and each leaf was categorized into the following classes: (1) no sign of herbivory, (2) damage to the leaf but portions of blade remaining, and (3) leaf blade totally consumed, only leaf rachis remaining. On 28 October 2004, one week following adult Cyphocleonus removal, all Centaurea leaves, damaged and undamaged, were counted again as a measure of compensatory response, or "tolerance" (Strauss and Agrawal 1999, Willis et al. 1999, MüllerSchärer et al. 2004) as recommended by Bossdorf et al.
(2005). Cyphocleonus larvae were allowed to grow and mature within Centaurea taproots until 11 November 2004 (205 days after planting), when plants were harvested. Taproots were then dissected using 5-30X magnification and all Cyphocleonus larvae were collected. The number of Cyphocleonus larvae within each Centaurea taproot was recorded, and each Cyphocleonus larva was weighed, measured in length, and preserved in a $90 \%$ ethanol solution. Centaurea plants were dried at $100^{\circ} \mathrm{C}$ for three days and weighed.

Centaurea plants from the same populations used for the paired experiment were also planted alone ( $n=50$ for each continent) to assess the performance of Cyphocleonus. Plants were grown in the same conditions as in the paired experiment, and on 14 November 2004, the number of Cyphocleonus larvae within each Centaurea taproot was recorded, larvae were weighed and measured in length, and preserved in a solution of $90 \%$ ethanol. However, not enough Cyphocleonus larvae developed and survived to test the effect of populations nested within regions, and therefore these results were tested with a $t$ test for the effect of region.

Agapeta zoegana.-We collected Agapeta moths in the field, within $5 \mathrm{~km}$ of Missoula, Montana, from 12 to 14 September 2004. On 15 May 2004, 50 2.4-L pots were prepared so that each contained one European Centaurea and one North American Centaurea. We used the same populations and the same pairs of populations in this experiment as in the paired Cyphocleonus experiment (Table 1). On 17 September 2004 (125 days after planting) small pieces $\left(<1 \mathrm{~cm}^{2}\right)$ of paper containing two to three Agapeta eggs from moths collected in the field were cut out by hand and pinned precisely in the middle between the European and North American Centaurea plants (see Thelen et al. 2005). As in the Cyphocleonus experiment, Centaurea plant basal rosette diameter was measured immediately prior to the introduction of Agapeta eggs to each pot so the effect of plant size on herbivore choice could be evaluated. Agapeta larvae were allowed to grow and mature within Centaurea taproots for over two months. On 7 December 2004 (206 days after planting) Agapeta larvae were weighed, measured in length, and preserved in a solution of $90 \%$ ethanol. Agapeta preferentially attack plants with larger taproots (Story et al. 2000), but Centaurea root caudex diameter was not a significant covariate.

At the same time the Centaurea plants were planted in pairs, individuals from the same populations were planted alone ( $n=50$ for each continent) to assess the performance of Agapeta. Plants were grown in the same conditions as in the paired experiment, and on 8 December 2004, the number of Agapeta larvae within each Centaurea taproot was recorded; larvae were weighed and measured in length, and preserved in a solution of $90 \%$ ethanol.

Trichoplusia ni.-We obtained Trichoplusia eggs from the New York State Agricultural Experiment Station in Geneva, New York. Eggs hatched 19 September 2004, 
TABLE 1. Summary of experimental results for Centaurea maculosa.

\begin{tabular}{lcccc}
\hline \hline \multicolumn{1}{c}{ Experiment } & $\begin{array}{c}\text { European and } \\
\text { North American replication }\end{array}$ & $\begin{array}{c}\text { Plant } \\
\text { growth }\end{array}$ & $\begin{array}{c}\text { Plant } \\
\text { reproduction }\end{array}$ & $\begin{array}{c}\text { Insect } \\
\text { development }\end{array}$ \\
\hline Growth & 14,11 & NA $\uparrow$ & NA $\downarrow$ & \\
Competition & 11,11 & NA $\uparrow$ & NA $\uparrow$ & \\
Cyphocleonus & 8,8 & NA $\uparrow$ & & NA $\downarrow$ \\
Agapeta & 8,8 & NA $\uparrow$ & & NA $\downarrow$ \\
Trichoplusia & 8,8 & & & NA $\downarrow$ \\
Melanoplus & 5,5 & NA $\uparrow$ & & NA $\downarrow$ \\
Maternal effects & 4,5 & & \\
\hline
\end{tabular}

Notes: Replication shows the number of populations used from each region, respectively. Upward-pointing arrows indicate that plants from North American (NA) populations grew larger, produced more flower heads, or inhibited insect growth more than the European populations; downward arrows indicate the reverse. For growth, the results for two of the four herbivory experiments are presented in Appendix D. The four species in column 1 are insect herbivores with which experiments were conducted. Empty cells indicate that no information is available.

and on that day one caterpillar was introduced to each of 30 2.4-L pots containing pairs of European and North American Centaurea, and 40 2.4-L pots containing a single European $(n=20)$ or North American $(n=$ 20) Centaurea plant. These plants were started from seed on 8 May 2004. We used eight populations from each continent for this experiment (Appendix A, Table 1), and these were chosen randomly from the total set of populations available. Each pair was established through random choices from the North American and European populations. For these paired combinations, specific pairs of populations were only used once. The paired Trichoplusia caterpillars were kept in their pots with cages made of transparent mesh, "bridal veil" fabric, and this mesh was also applied to Centaurea without insects as a methodological control. In the paired experiment, Trichoplusia could select a European or North American Centaurea, and this experiment was used to quantify host choice. In the single-host-plant experiment, we measured Trichoplusia growth rate, final mass prior to pupation, pupation rate, and adult emergence. Each caterpillar was weighed daily until pupation. Once pupation was no longer occurring (42 days after application and 184 days after planting), all leaves of each Centaurea plant (paired and single) were counted and placed into the following classes: (1) no sign of herbivory; (2) damage to the leaf but portions of blade remaining; and (3) leaf blade totally consumed, with only the leaf rachis remaining.

We statistically analyzed the damage done to Centaurea plants by Trichoplusia and the final mass and growth rate of Trichoplusia caterpillars using the nested ANOVA procedure. Differences in proportion emerged and proportion pupated among Trichoplusia on Centaurea from different regions were compared by fitting nontransformed survival numbers to log-normal distribution curves and testing the whole model and paired treatments with chi-square analyses. We did not include population as a factor in these analyses.

Melanoplus sanguinipes.-Beginning on 3 December 2004 we grew individual Centaurea plants from seed from five different populations of European Centaurea and five different populations of North American Centaurea (Table 1, chosen randomly from available populations). On 17 February 2005 Centaurea root caudex diameters were measured using calipers as an initial metric of plant performance, prior to herbivore application. We used 10 replicates of each population for the herbivore treatment and another 10 replicates for controls, for a total of 100 plants per region.

On 18 February 2005 (71 days after planting), thirdinstar Melanoplus were obtained from Stefan Jaronski at the USDA Agricultural Research Station (ARS) in Sidney, Montana and on 19 February 2005 these insects were introduced to Centaurea plants. Two Melanoplus were applied to each of the 100 Centaurea plants. Pots were covered with "bridal veil" fabric. All Melanoplus treatment pots were monitored daily for insect mortality. Initially, Melanoplus mortality was high (possibly due to stress related to shipping), and on 23 February 2005 all dead Melanoplus were removed from pots, and herbivore density was adjusted (either dead insects replaced with live ones or insects removed) so that each Melanoplus treatment pot contained one insect. At this time, all Melanoplus were weighed, body length measured, and current instar recorded for initial pretreatment metrics. Over the next 30 days, insect body length, mortality, and instar were measured four more times, and the experiment ended on 22 March 2005.

We analyzed the effects of North American and European Centaurea on mass and length growth rates of Melanoplus using the nested ANOVA procedure. However, differences in the numbers of Melanoplus at the fourth instar, fifth instar, or adult stage were tested using chi-square analysis.

\section{Biogeographic differences in defense traits and plant nutrition}

We measured leaf chemistry and toughness (see Coley 1983) for all European and North American Centaurea used in the Agapeta experiment, described above. On 29 November 2004, one week prior to Agapeta larval harvest, one leaf that showed no signs of physical damage or discoloration from each Centaurea plant was 
removed, and preserved in plastic tubes on dry ice until analysis of volatile herbivore defense compounds was completed. Sample leaves were ground with ethyl acetate ( $1 \mathrm{~mL} / 0.1 \mathrm{~g}$ sample mass) at room temperature, and then transferred to a glass tube. The glass tube was shaken for $10 \mathrm{~min}$ at $200 \mathrm{rpm}\left[2550 \mathrm{~m} / \mathrm{s}^{2}\right]$, and centrifuged for 10 $\min (2000 \mathrm{rpm})$. Supernatant fluids were filtrated (Superclean Envi-carb tubes; SUPELCO, Bellefonte, Pennsylvania, USA) and $1 \mu \mathrm{L}$ of the supernatant was analyzed using a gas chromatograph/mass spectrometer (Hewlett-Packard 5890 series II, Avondale, Pennsylvania, USA) equipped with a $30 \mathrm{~m} \times 0.25 \mathrm{~mm}$ capillary column (DB-5.625; J\&W Scientific, Folsom, California, USA) with helium as the carrier gas. The initial oven temperature was maintained at $0^{\circ} \mathrm{C}$ for eight minutes by cryogenic cooling. The oven temperature was increased to $70^{\circ} \mathrm{C}$ at rate of $7^{\circ} \mathrm{C} / \mathrm{min}$, and then to the final temperature of $300^{\circ} \mathrm{C}$ at the rate of $20^{\circ} \mathrm{C} / \mathrm{min}$, which was maintained for $10.5 \mathrm{~min}$. The injection port temperature was $250^{\circ} \mathrm{C}$, and the helium carrier gas linear velocity was maintained at $35 \mathrm{~cm} / \mathrm{s}$ with automated pressure control. Detection was achieved by mass-selective detection (Hewlett-Packard 5972) in the scan mode (mass to charge ratio: 33-500). The chemical structures were identified by using a Wiley $138-\mathrm{K}$ mass spectral database (John Wiley and Sons, New York, New York, USA), and by comparing the mass spectra and the retention time with those of authentic chemical samples. Quantitative analysis is possible by measuring the relative "ion intensities" produced by the mass spectra (see Arimura et al. 2000).

On 6 December 2004, immediately prior to Agapeta larval harvest, two healthy leaves from each Centaurea plant were also analyzed for leaf toughness (a potential anti-herbivore defense mechanism) using a penetrometer (John Chatillon and Sons, Scales and Force Measuring Instruments, New York, New York, USA), which measures the grams of force required to punch through a particular leaf. Punches were taken $1 \mathrm{~cm}$ from the leaf tip and equally distant from the mid-vein and the edge of the leaf.

We conducted an additional greenhouse experiment to ascertain if leaf nutrition and trichomes play a role in differences between the defense capabilities of North American and European Centaurea. We measured leaf trichome density and leaf carbon and nitrogen concentration on 11 North American populations and 11 European populations of Centaurea. On 20 December 2005 we planted six seeds per population in each of 10 2.4-L pots (220 total pots) and several weeks later thinned the germinants to one individual per pot. Our final replication was 49 North American individuals from 10 populations and 50 European individuals from nine populations. On 13-15 March 2006 (85-87 days after planting) leaf trichome density was measured on two apparently healthy leaves taken from each plant. We collected one disc, $28.3 \mathrm{~mm}^{2}$ in area, from each of the two leaves with a metal paper punch, with discs collected 1 $\mathrm{cm}$ from the leaf tip and equally distant from the midvein and the edge of the leaf. Trichome density was counted at 5-30× magnification. All plants were then dried at $60^{\circ} \mathrm{C}$ for three days, weighed, and the shoots were ground and prepared for carbon and nitrogen content analysis. Carbon and nitrogen content analysis was measured using a CE Instruments EA 1100 CHNSO Elemental Analyzer (CE Instruments, Wigan, UK).

\section{Catechin production}

We measured Centaurea catechin production in four populations of European Centaurea and 11 populations of North American Centaurea. Replication was limited to four populations for European Centaurea because we could not successfully sterilize the seeds from many of the populations we possessed, and therefore could not rule out microbial contaminants as a source of catechin. Results from these populations are not included here. For each population we initially processed five replications, consisting of three individuals grown in $3 \mathrm{~mL}$ of Murashige and Skoog (1962) medium (MS). However, due to poor germination the final replication for three of the populations was reduced to three. Fifteen-day-old Centaurea plants were grown in $50-\mathrm{mL}$ glass tubes containing $3 \mathrm{~mL}$ sterile MS medium on an orbital platform shaker for seven days. After seven days, the medium was collected, filtered through Whatman filter paper to remove debris, and extracted in a separating funnel three times using an equal volume of acidified ethyl acetate (1\% acetic acid). Samples were concentrated under $\mathrm{N}_{2}$, and resuspended in $500 \mu \mathrm{L}$ methanol. Methanol extracts were chromatographed (High Performance Liquid Chromatography, Dionex Summit System, Sunnyvale, California, USA) on a reverse-phase 5$\mu \mathrm{m}, \mathrm{C}_{18}$ column $(25 \mathrm{~cm} \times 4.6 \mathrm{~mm})$ (Supelco) using a multistep gradient. The absorbance at the reference wavelength, $\lambda_{\max }, 280 \mathrm{~nm}$ was measured by a PDA-100 Photodiode array variable UV/VIS detector (Dionex Company). Mobile phase solution A consisted of double-distilled water containing $0.1 \%$ acetic acid and solution B consisted of ACS grade methanol (Fisher Scientific, Pittsburgh, Pennsylvania, USA). A multistep gradient was used for all separations with an initial injection volume of $20 \mu \mathrm{L}$ and a flow rate of $1 \mathrm{~mL} / \mathrm{min}$. The multistep gradient was as follows: $0-5 \min 5.0 \% \mathrm{~B}$, $5-10 \min 20.0 \%$ B, 15-20 min $20.0 \%$ B, 20-40 $\min 80.0 \%$ B, 40-60 min $100 \% \mathrm{~B}, 60-70 \mathrm{~min} 100 \% \mathrm{~B}, 70-80 \mathrm{~min}$ $5.0 \%$ B. In each sample, $( \pm)$-catechin concentrations were determined by comparison to $20-\mu \mathrm{L}$ injections from a $1 \mathrm{mg} / \mathrm{mL}$ catechin standard stock.

\section{Maternal effects}

Eight Centaurea plants from each of the same eight European populations and eight North American populations used in the Cyphocleonus, Agapeta, and Trichoplusia herbivore treatment experiments were grown to maturity and allowed to flower. Seeds were planted on 9 May 2005. Pollen was transferred among 
all plants within a population in three sessions between 6 and 8 November 2005, 180 days later. In each session, this was done by touching the stamens on a single flower on a randomly chosen plant with a size-7 watercolor paint brush (Rhapsody, Raleigh, North Carolina, USA) and then touching the paintbrush to a single flower on another randomly chosen plant, and doing this consecutively until 10 flowers on each of the eight plants had been touched. Flower heads were collected and counted, and their seeds were removed and counted. However, we were only able to obtain viable seeds from four European and five North American populations, and only 2-19 seeds per population. On 21 December 2005 all of these maternal line seeds were planted individually in the greenhouse in 2.4 -L pots to determine if two of the more salient biogeographic trait differences, total plant mass and leaf toughness, could be explained by maternal effects rather than genetically based population differences. On 15 March 2006, two leaves that showed no sign of damage or discoloration from each maternal line Centaurea plant were analyzed for leaf toughness. On 16 March 2006 (85 days after planting) all plants were harvested, dried at $100^{\circ} \mathrm{C}$ for three days, and weighed (in grams).

\section{Soil effects}

An important limitation of our experimental design was that we added only North American soils to the sand used in the growth, competition, and herbivore experiments. Our intention was to provide AM fungi and other soil biota so that C. maculosa was grown in a more ecologically realistic environment (Callaway et al. 2004). Only later did we realize that if North American populations had adapted in some way to North American soil biota we could have biased our results. Therefore we conducted an experiment in which we selected six North American and six European populations (for which we had collected soil and seeds from the same sites) and grew each population in soil from its native home site and in soil from a randomly selected soil from the nonnative range. We used the same mix of $20 \%$ soil: $80 \%$ sand. The idea was to determine if North American plants benefit more than European plants from North American soil. For each of the six populations we began with 16 replicates but after mortality the total was $n=170$ for the experiment, with 12-16 replicates for each North American population and 10-16 for each European population.

\section{RESULTS}

Germination, growth, fitness, and competitive ability

The mean germination rate of Centaurea from North American populations was $81 \%$ higher than that of European populations (Appendix C, ANOVA with logtransformed data; age [covariate], $F_{1,15}=1.55, P=0.236$; region, $\left.F_{1,15}=8.90, P=0.011\right)$. The age of the collected seed did not affect germination.
In a second experiment with plants grown alone, the total biomass of Centaurea plants from North American populations averaged $30 \%$ greater than that of European populations (Fig. 1A; ANOVA table in Appendix B, region, $P>0.001)$. The average flower head number of European populations tended to be higher than that of North Americans but the effect of region was not significant $(P=0.065 ;$ Fig. 2A; ANOVA table in Appendix B).

Competition with Pseudoroegneria reduced the mass of plants from North American populations by $25 \%$, but reduced the mass of plants from Europe by 58\% (Fig. 1B). The flower head production of North American plants was reduced by less than $40 \%$ by competition, whereas European flower head production was reduced by over $80 \%$ (Fig. 2B).

When competing against $C$. maculosa plants from North American populations, both Pseudoroegneria and Festuca had significantly less total mass than when they were grown in competition with Centaurea from European populations (Fig. 3).

For the comparison of tetraploid populations from North America and Europe, the mean diameter of the rosette for North American plants was $33.3 \pm 1.0 \mathrm{~cm}$ (mean $\pm \mathrm{SE} ; n=30$ individuals) vs. $20.9 \pm 1.0 \mathrm{~cm}(n=$ 30 individuals) for European plants (in an ANOVA with region as a fixed variable and population as a random variable: region, $F=38.38 ; \mathrm{df}=1,7, P<0.001$; population, $F=1.78$, df $=8,43, P=0.235)$.

\section{Plant-herbivore interactions}

Cyphocleonus achaetes.-In the experiment with paired plants, Cyphocleonus adults preferentially grazed upon European Centaurea leaves, heavily damaging (consuming the entire leaf down to the rachis) more than twice as many leaves of European Centaurea plants as leaves of North American plants (Fig. 4A, ANOVA table in Appendix B). Similar numbers of Cyphocleonus larvae were discovered in the taproots of European and North American plants in this experiment (12 vs. 13, respectively).

In the second experiment with solitary Centaurea plants, individual larvae consuming taproots of European Centaurea plants $(123.4 \pm 17.6 \mathrm{mg}$; mean $\pm \mathrm{SE})$ were $57 \%$ larger than those recovered from North American plants (78.4 \pm 12.7$)$. However, not enough Cyphocleonus larvae developed and survived to test the effect of populations nested within regions, and therefore these results were tested with a $t$-test for the effect of region (region $t=2.11$, $\mathrm{df}=1,23, P=0.045$ ).

For solitary Centaurea plants, plant mortality in the Cyphocleonus treatment was high, with $66 \%$ of all experimental plants in both experiments dying by the end of the experiment. However, nearly twice as many North American Centaurea plants survived Cyphocleonus herbivory as European plants (data not shown). One week after removing Cyphocleonus adults, North American plants had produced $5.7 \pm 0.3$ new leaves per plant 

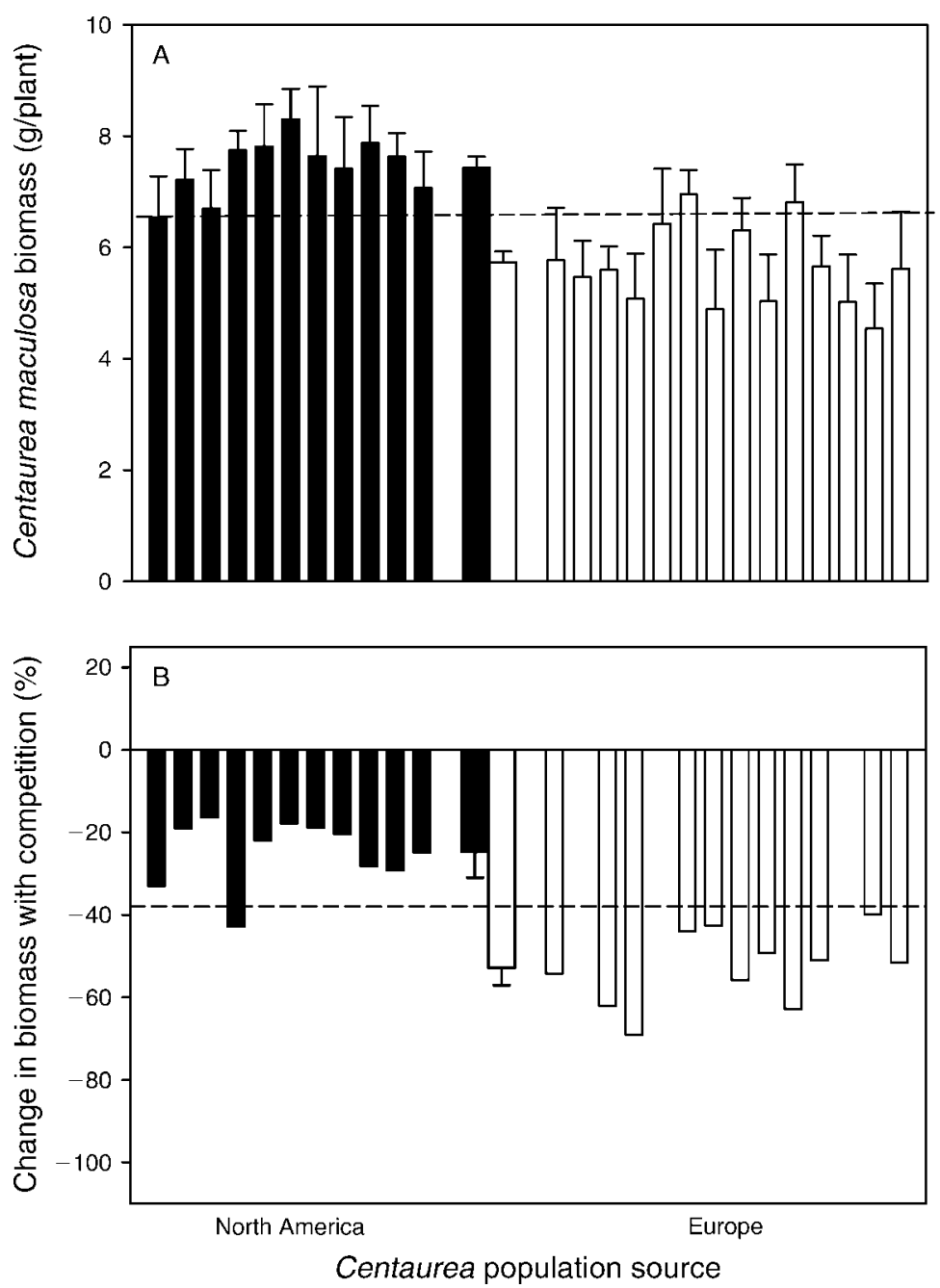

FIG. 1. (A) Total biomass of Centaurea maculosa from North American and European populations without competition. Narrow bars depict means and SE for each population; two thicker bars in the center are means and SE for each region using the means of each population as replicates. The dashed line shows the mean for all populations. Results from ANOVA: region, $F_{1,23}=$ 43.79, $P<0.001$; population, $F_{23,145}=0.86, P=0.657$ (ANOVA table is in Appendix B). (B) The response of Centaurea to competition from the native grass Pseudoroegneria spicata as the percentage decrease in biomass. The mean for each population is presented in the narrow bars; means and SE for each region are presented in the two thicker bars in the center of the figure. The dashed line shows the mean for all populations. In a $t$ test with populations as independent samples, region $t_{1,21}=7.70, P<0.001$. Populations are matched in panels A and B, but there are fewer populations in panel B because mortality with competition reduced the sample size in some European populations to one or two individuals.

vs. $4.0 \pm 0.5$ for European plants (ANOVA with larval mass as a covariate; region $F_{1,14}=13.95, P<0.001$; population $F_{14,69}=0.91, \mathrm{df}=7,47, P=0.512$ ). Of those plants living at the end of the experiment, North American Centaurea mass was 35\% larger than that of European plants (Appendix D, Fig. 2B).

Agapeta zoegana.-Prior to application of insect treatments in the paired plant experiments, basal rosette diameter of North American plants was $14 \%$ larger than European plants and North American caudex diameters were nearly twice as large as those of European plants. But even though North American plants were larger, and Agapeta prefers to infest larger plants (Story et al. 2000), Agapeta larvae preferentially chose European plants in the paired plant experiment (Fig. 5). However, in the experiment with Centaurea planted alone, the total mass of Agapeta larvae per individual Centaurea plant did not differ significantly among North American and European Centaurea populations (Fig. 5; region, $F_{1,59}=2.22, P=0.1498$, Appendix B). The total mass of North American Centaurea plants in the paired-plant experiment was $30 \%$ greater than that of European plants (Appendix D, Fig. 2A).

Trichoplusia ni.-When reared on paired European and North American Centaurea plants, Trichoplusia severely damaged (left nothing but the leaf rachis) European Centaurea leaves five times more frequently than North American leaves (data not shown; ANOVA 

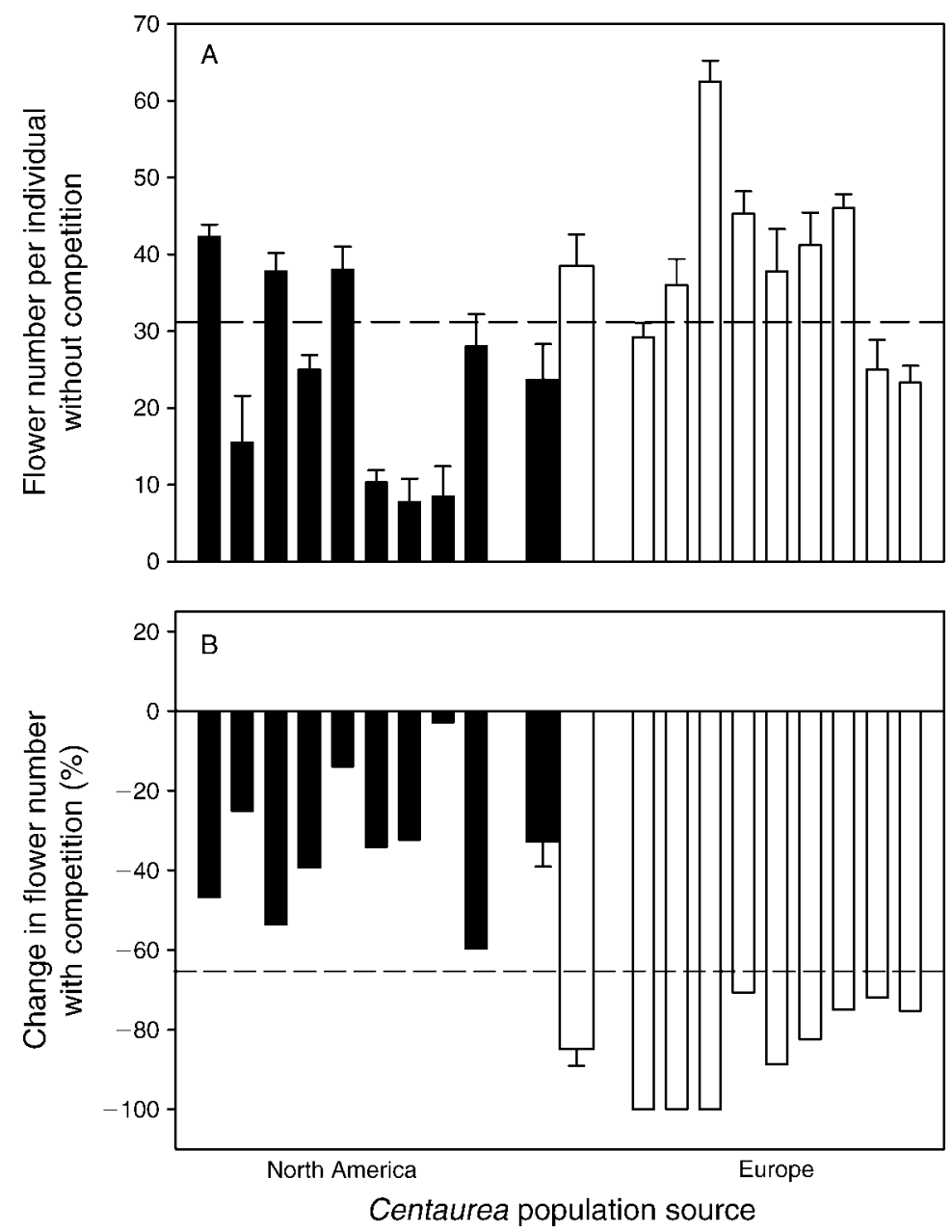

FIG. 2. (A) Flower head production of Centaurea maculosa from North American and European populations. The narrow bars show means and SE for each population; the two thicker bars in the center of the figure show means and SE for each region using the means of each population as replicates. The dashed line shows the mean for all populations. Results from ANOVA (full table is in Appendix B): region, $F_{1,16}=3.91, P=0.0652$; population, $F_{16,114}=5.68, P<0.001$. (B) The response of Centaurea to competition from Pseudoroegneria as the percentage decrease in flower head production. The mean for each population is presented in the narrow bars; means and SE for each region are presented in the two thicker bars in the center of the figure. In a $t$ test with populations as independent samples, $t_{1,17}=9.44, P<0.001$. Populations are matched in panels A and B.

region, $F_{1,15}=9.22, P<0.001$; population $F_{1,15}=5.35$, $P=0.007$, Appendix B). Trichoplusia preferentially grazed upon European Centaurea, heavily damaging $12 \%$ of the leaves of European Centaurea compared to only $1 \%$ of North American Centaurea leaves (Fig. 4B). For North American plants, 20\% more leaves remained completely undamaged by these generalist herbivores than leaves on European plants (Fig. 4B).

Trichoplusia caterpillars fed only European Centaurea grew more than twice as fast as caterpillars feeding on North American conspecifics (Fig. 6A; Appendix B). Moreover, Trichoplusia caterpillars averaged $28 \%$ larger final mass prior to pupation when consuming European Centaurea leaves (Fig. 6B). All Trichoplusia caterpillars pupated by 26 days on European Centaurea, whereas only $70 \%$ of those reared on North American plants had pupated by 26 days (Fig. 6C). All Trichoplusia reared on
European plants emerged as adult moths by 35 days, but only $40 \%$ of those reared on North American plants had emerged as adults by the 35th day (Fig. 6D).

Melanoplus sanguinipes.-Mortality of the native North American generalist, Melanoplus, was much higher than that of the naturalized European generalist, Trichoplusia, but mortality was similar for Melanoplus reared on North American and European populations in isolated plant experiments (data not shown). However, Melanoplus grew $127 \%$ faster in length (Fig. 7A) and acquired mass $156 \%$ faster when feeding on European plants than on North American plants (data not shown, ANOVA table in Appendix B). Moreover, 56\% more Melanoplus reached maturity prior to senescence when feeding on European plants than when feeding on North American Centaurea (Fig. $7 \mathrm{~B} ; \chi^{2}=13.2$, df $=6, P<$ $0.05)$. 

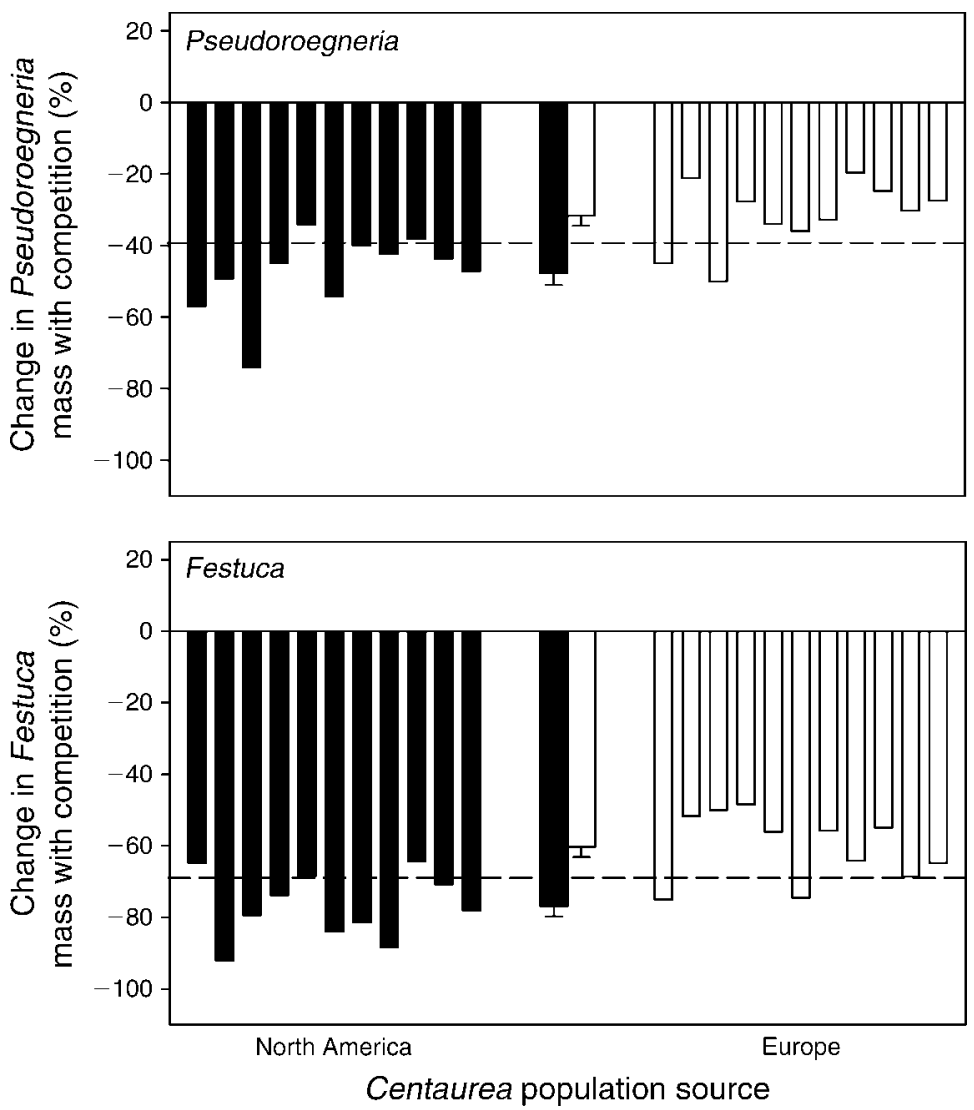

FIg. 3. The response of two native North American grasses, Pseudoroegneria spicata and Festuca idahoensis, to competition from Centaurea, as the percentage decrease in grass biomass when grown with Centaurea vs. alone. The mean for each population is presented in the narrow bars, and means and SE for each region are presented in the two thicker bars in the center of the panels. The dashed lines show the means for all populations. In $t$ tests with populations as independent samples, for Pseudoroegneria, region $t_{1,21}=16.04, P=0.001$; for Festuca, region $t_{1,21}=13.50, P=0.002$.

\section{Mechanisms of Centaurea resistance to herbivores}

Leaves on plants from North American populations contained approximately two times higher concentrations of the defense compound precursor, phytol, in their leaves than European populations (Fig. 8A). For another defense compound precursor, germacrene D, the trend was the same but there was no significant difference for plants among regions. North American Centaurea leaves were also $166 \%$ tougher when tested with a leaf penetrometer than European conspecifics (Fig. 8B). North American Centaurea leaves had 42\% more glandular trichomes than leaves on European plants (Fig. 8C). Leaves from European Centaurea had significantly higher percent $\mathrm{N}$ than North American Centaurea (Fig. 8D; region, $F=6.21, P=0.0214$ ), but leaf $\mathrm{C}: \mathrm{N}$ ratios were almost identical between biogeographic regions (data not shown).

\section{Biogeographic differences in Centaurea catechin production}

Mean ( \pm )-catechin concentrations in solutions containing North American Centaurea seedlings was $42 \pm$
$12 \mu \mathrm{g} / \mathrm{mL}$ (mean $\pm \mathrm{SE}$ ), compared to $24 \pm 0.09 \mu \mathrm{g} / \mathrm{mL}$ in solutions containing European conspecifics, but there was no significant difference between regions (ANOVA; region, $F_{1,11}=3.18, P=0.1002$; population, $F_{11,46}=$ $1.98, P=0.0527$.

\section{Maternal effects}

For $\mathrm{F}_{1}$ lines, the average total biomass of North American Centaurea was $152 \%$ greater than the average total biomass of European Centaurea (Fig. 9; Appendix B). Leaf toughness followed the same pattern. The average leaf toughness of North American Centaurea was $81 \%$ greater than the average leaf toughness of European Centaurea. There was no overlap in the means of any North American and European population for either variable.

\section{Soil effects}

Again we found that plants from North American populations were larger $(0.53 \pm 0.18 \mathrm{~g}$ per plant vs. 0.38 \pm 0.015 ; region $F<0.001$ ), but all populations grew best in European soil, suggesting that European soil was more fertile. Moreover, there was no interaction 


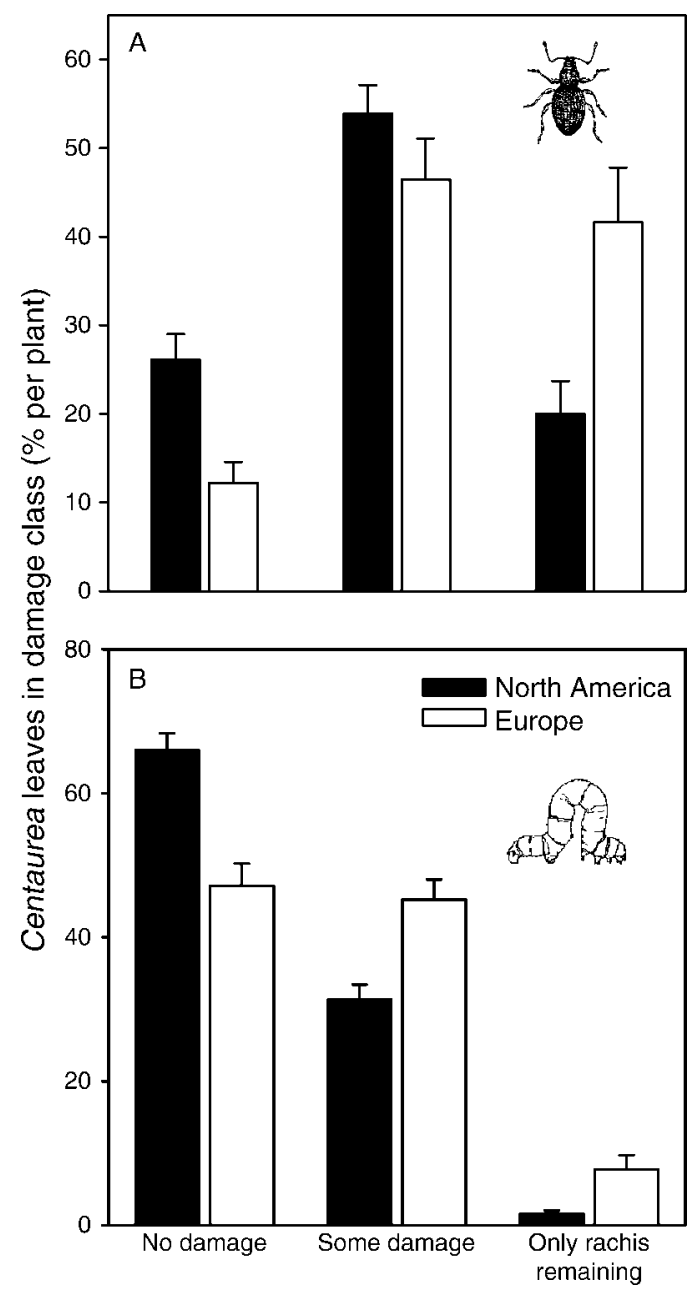

FIG. 4. (A) Damage rankings for North American and European Centaurea maculosa plant pairs subjected to leaf herbivory by the adults of the specialist weevil Cyphocleonus achates. Bars show percentage distribution (mean $+\mathrm{SE}$ ) of leaves per plant in damage classes. ANOVA (Appendix B) for the "no damage" class: region, $F_{1,14}=5.91, P=0.0205$; population, $F_{14,69}=0.27, P=0.9874$. For the "some damage" class: region, $F_{1,14}=1.32, P=0.2580$; population, $F_{14,69}=0.73$, $P=0.7343$. For the "only rachis remaining" class: region, $F_{1,14}$ $=8.58, P=0.0057$; population, $F_{14,69}=0.79, P=0.6733$. (B) Damage ranking for North American and European Centaurea maculosa grown in North American-European pairs, subjected to leaf herbivory by caterpillars of the naturalized European generalist herbivore, Trichoplusia ni. Bars show percentage distribution (mean $+\mathrm{SE}$ ) of leaves per plant in damage classes. ANOVA (Appendix B) for the "no damage" class: region, $F_{1,14}$ $=125.86, P<0.0001$; population, $F_{14,24}=0.52, P=0.8986$. For the "some damage" class: region, $F_{1,14}=0.76, P=0.3972$; population, $F_{14,24}=1.23, P=0.3169$. For the "only rachis remaining" class: region, $F_{1,14}=17.35, P=0.0008$; population, $F_{14,24}=1.0, P=0.4510$.

between the effects of the region of soil collection and the region of seed collection $(F=1.04, \mathrm{df}=1,170, P=$ 0.308 ). In other words, we found no evidence that plants from North American populations were larger than plants from European populations because they were growing in substrate containing soil from North America.

\section{Discussion}

We found that plants from North American Centaurea populations were bigger, elicited stronger competitive effects, and demonstrated stronger competitive responses than European populations (Table 1). Almost all previous similar studies of populations in the invaded and native ranges of an invasive species have compared growth or biomass, and inferred increased competitive ability from these metrics. We found that measurements of competitive effect and response show stronger biogeographical difference in comparisons of European and North American Centaurea populations than measurements of plant size or reproduction. For example, European Centaurea plants tended to produce more flower heads than North American plants when grown without competition, but when grown with
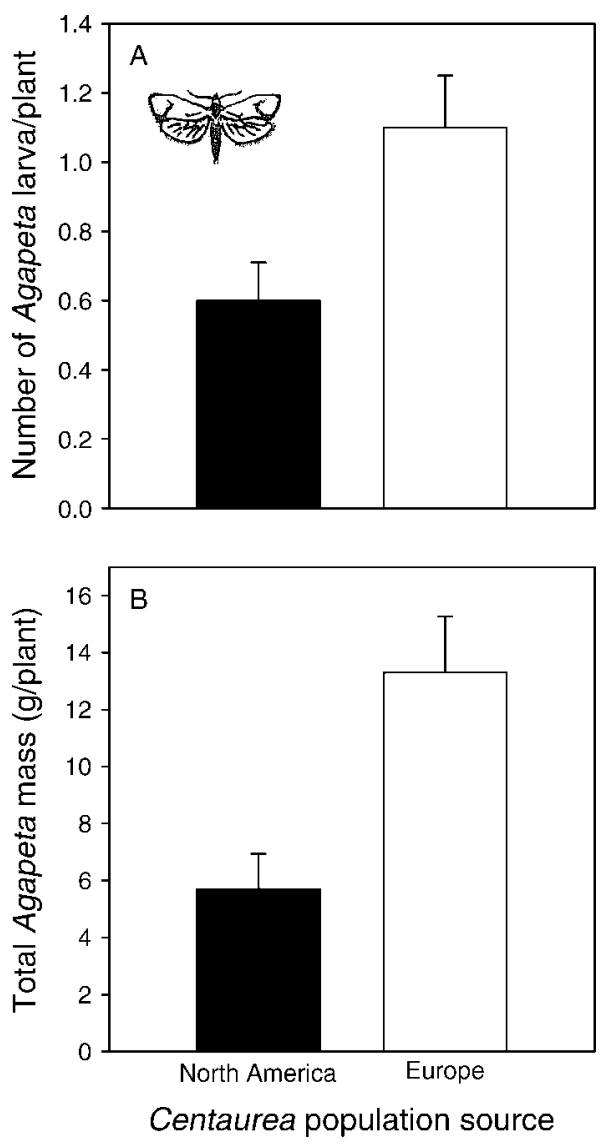

FIG. 5. (A) Mean number of Agapeta zoegana larvae infesting taproots of individual North American and European Centaurea maculosa plants planted in North-American-Europe pairs. ANOVA: region, $F_{1,15}=5.25, P=0.025$; population, $F_{15,82}=1.35, P=0.240$. (B) Total mass of Agapeta larvae per individual North American and European $C$. maculosa plant (full tables are in Appendix B). ANOVA: region, $F_{1,11}=2.22 ; P$ $=0.1498$; population, $F_{11,59}=0.95, P=0.5017$. Error bars represent $+\mathrm{SE}$. 

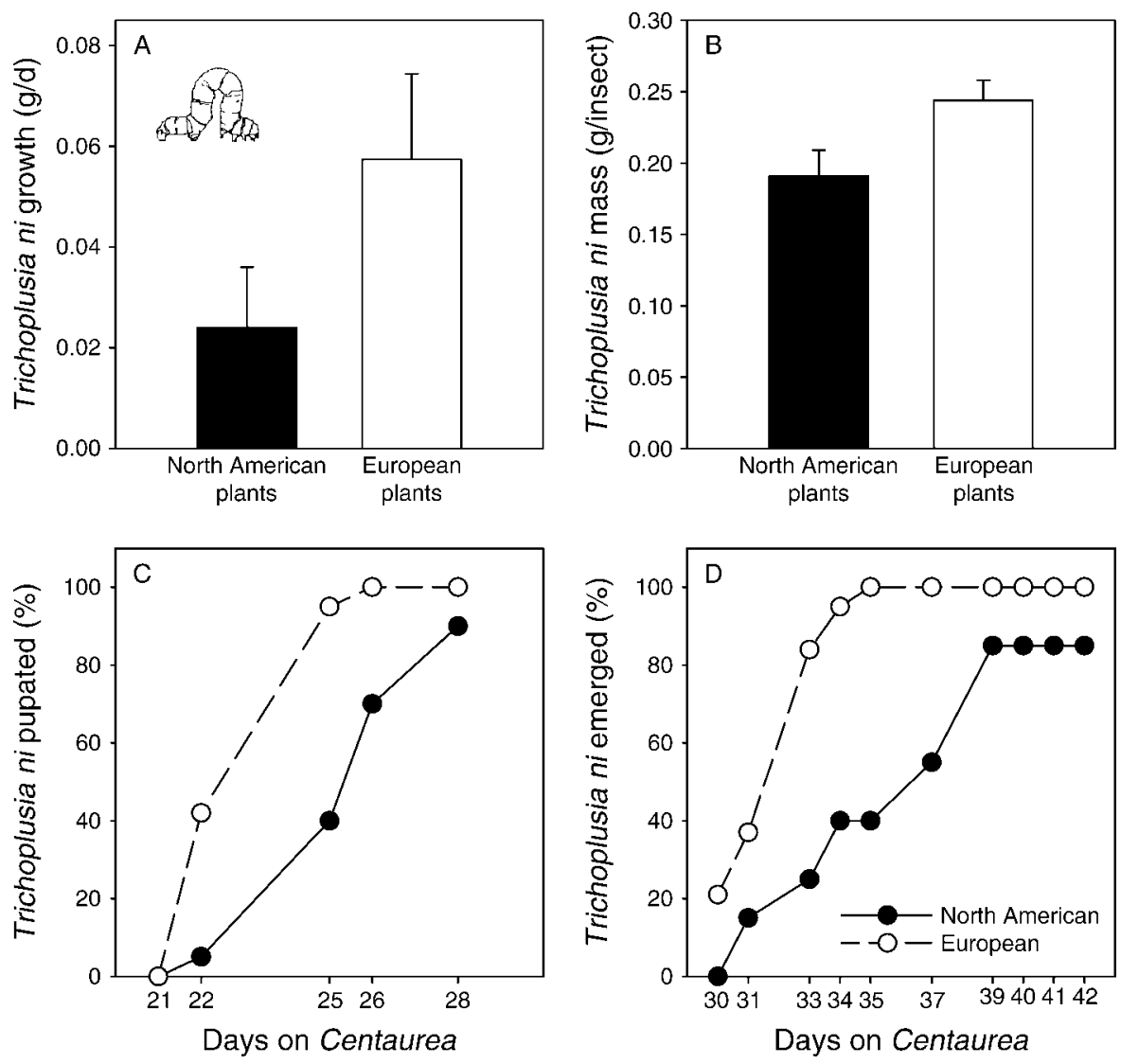

FIG. 6. The effect of North American or European Centaurea maculosa plants on the performance of the generalist European herbivore Trichoplusia ni. In all panels, error bars show SE. (A) Growth rates of T. ni on North American or European Centaurea. ANOVA (full tables are in Appendix B): region, $F_{1,14}=5.62, P=0.0313$; population, $F_{14,24}=0.830, P=0.6374$; initial mass[covariate], $F_{1,24}=8.12 ; P=0.009$. (B) Final $T$. ni mass on North American or European Centaurea. ANOVA with initial caterpillar mass as a covariate: region, $F_{1,14}=4.05, P=0.0628$; population, $F_{14,24}=1.28, P=0.2887$; initial mass [covariate], $F_{1,24}=$ 40.62, $P<0.001$. (C) Pupation rates of $T$. $n i$ on North American or European Centaurea. (D) Adult emergence rates of $T . n i$ on North American or European Centaurea.

competitors, European populations produced far fewer flower heads than North American populations.

All differences in traits between North American and European Centaurea populations occurred under identical conditions in greenhouses, so phenotypic plasticity can be ruled out as a cause (Reznick and Ghalambor 2001). However, our design did not take into account the likelihood that these regional differences will vary in different abiotic conditions, as demonstrated by Maron et al. (2004). Furthermore, even though our experiments suggest that North American Centaurea populations have evolved to be better competitors, as for virtually all studies of the evolution of invasives we cannot rule out founder effects. Total biomass remained substantially larger for North American populations even after growing populations in common conditions for a generation, reducing the potential of maternal effects to explain our results (Rossiter 1996). However, our experiment on maternal effects is limited because of very low replication among and within populations.

\section{Trade-offs vs. direct selection}

If indeed Centaurea has evolved to be larger and more competitive in North America, this supports one part of the "evolution of increased competitive ability" hypothesis (Blossey and Notzold 1995). However, North American Centaurea genotypes were also consistently better defended against (or avoided by) specialist and generalist consumers, demonstrating both a stronger inhibitory effect on the consumers (resistance) and a better ability to grow in response to herbivory (tolerance), which questions the trade-off based assumptions of EICA as a consistent mechanistic basis for the continental differences between populations of invaders. Our results suggest that the evolution of increased competitive ability may not always require physiological trade-offs between the allocation of energy or resources to growth or to defense. Our results also suggest that the broader "grow or defend" conceptual foundation of EICA theory, developed by Herms and Mattson (1992), may not always constrain the evolution of competitive 

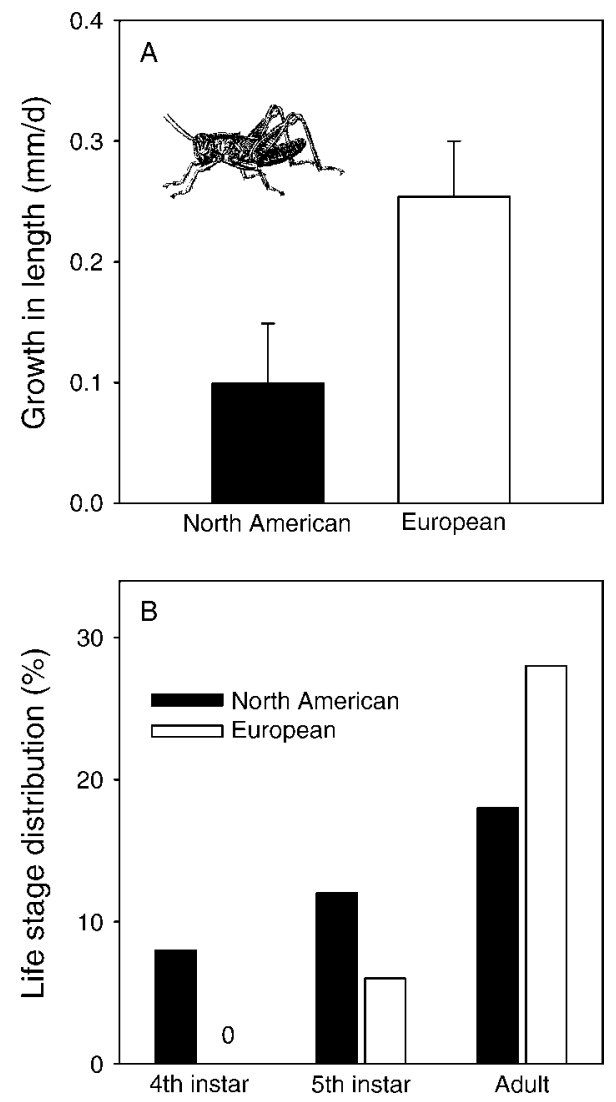

FIG. 7. The effect of North American or European Centaurea maculosa plants on the performance of the generalist North American herbivore, Melanoplus sanguinipes. (A) Growth rates in length of Melanoplus on North American or European Centaurea. ANOVA (Appendix B): region, $F_{1,8}=$ $26.88, P=0.0001$; population, $F_{8,32}=0.50, P=0.8490$; initial length [covariate], $F_{1,32}=4.00, P=0.028$. Error bars show SE. (B) Percentages of surviving Melanoplus at different life stages on North American or European Centaurea plants at the time some host plants began to senesce $\left(\chi^{2}=13.2, \mathrm{df}=6, P<0.05\right)$. Percentages do not add to $100 \%$ for a region because they incorporate mortality.

and defensive traits. Using a model from the optimal defense literature, Zhang and Jiang (2006) argued that enemy release is neither sufficient nor necessary for evolution of reduced resistance in introduced plants to occur when habitat productivity covaries. However, there is a possibility of a trade-off between reproduction and defense, as European Centaurea tended (region $P=$ $0.0652)$ to produce more flower heads than North American Centaurea in the absence of competition and herbivory. In other words, Centaurea plants from European populations may behave like ruderals, allocating more to dispersal, whereas North American Centaurea appear to have shifted allocation toward growth and defense, as would be expected of a "good competitor" (Grime 1977).

What might be an alternative to trade-off-based evolutionary changes in competitive ability and defense for invasives? First, defenses against herbivores gener- ally come at some physiological cost (McKey 1974, Agren and Schemske 1992). However, others have not found defense costs and suggested costs may be minimal or that costs may only be manifest in terms of broader life history traits, "multiple costs" or "alternative defense strategies" (Agrawal and Karban 1999, Agrawal and Fishbein 2006). Along these lines we suggest that selection for effective competitive or defense traits may not be easily coupled to resource or energetic trade-offs for a simple reason; different defense or allelopathic chemicals may cost the same energetically or nutritionally, but differ a great deal in effectiveness. The effectiveness of a biochemical reduces its relative cost (Siemens et al. 2002). In other words, physiological costs of a biochemical may be trivial in an ecological context if the biochemical is exceptionally effective or performs more than one job.

In this context, there is evidence that Centaurea is allelopathic and $( \pm)$-catechin is an active biochemical agent of phytotoxicity (Buta and Lusby 1986, Ridenour and Callaway 2001, Bais et al. 2003, Iqbal et al. 2003, Weir et al. 2003, 2006, Callaway et al. 2005, Perry et al. 2005b, Thelen et al. 2005, D'Abrosca et al. 2006; Simões et al., in press; Inderjit, unpublished data; but see Blair et al. 2005, 2006). Furthermore, there is evidence that ( \pm )catechin, and allelopathic chemicals from other Centaurea species, are more toxic to naïve North American species than to European species in their native communities; the "novel weapons hypothesis" (Callaway and Aschehoug 2000, Bais et al. 2003, Callaway and Ridenour 2004, Vivanco et al. 2004; W. He, Y. Feng, and R. M. Callaway, unpublished data). Regardless of the factors that originally select for the chemical composition of root exudates of a particular species (e.g., nutrient chelation, offense, defense, or microbial interaction), the novelty of a biochemical may correlate with its superior effectiveness because new and naïve neighbors would not have had the opportunity to evolve tolerance or resistance (see Cappuccino and Carpenter 2005, Carpenter and Cappuccino 2005, Cappuccino and Arnason 2006). If invaders possess traits, such as allelochemical weapons or defense chemicals, that provide greater competitive or defense advantages in their new habitats than in their original ranges, then selection pressure for the traits conferring competitive advantages may be greater on the genotypes in the invaded regions than on the conspecific genotypes remaining at home. In other words, individuals that produce larger amounts of unusually effective defense or allelopathic chemicals might grow and reproduce more than individuals that do not, resulting in adaptive evolution driven by selection on specific biochemistry, the "allelopathic advantage against resident species" or AARS hypothesis derived from the novel weapons hypothesis and proposed by Callaway and Ridenour (2004). We found support for such directional selection in higher amounts of defense precursors produced by North Americans (Fig. 9) and a trend (region $P=$ 

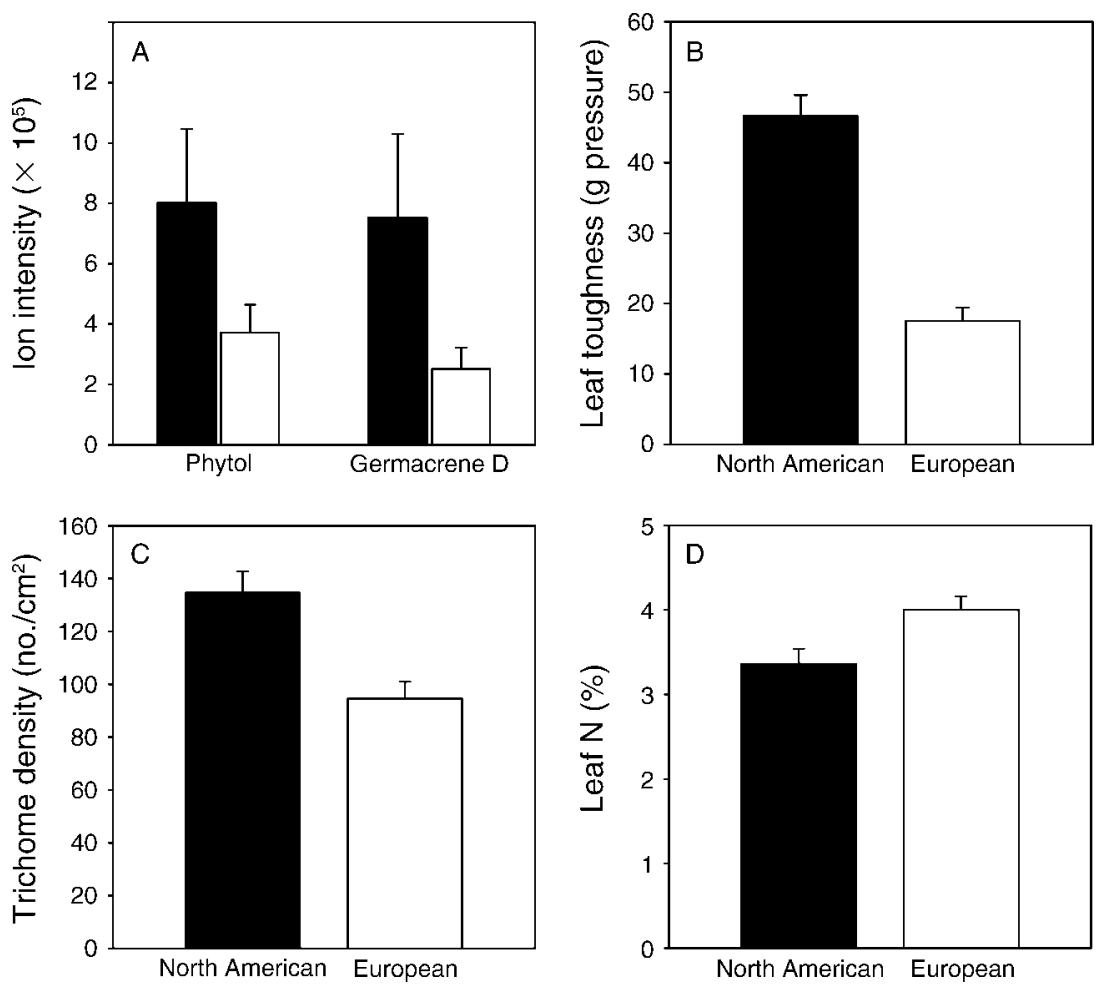

FIG. 8. Potential mechanisms by which North American populations of Centaurea maculosa could derive greater resistance to herbivory than European populations. For all measurements only Centaurea plants free from herbivory were used. Error bars show SE. (A) Leaf concentrations of the defense compound precursors phytol (ANOVA: region, $F_{1,13}=4.64, P=0.0451$ ) and germacrene D (ANOVA: region, $F_{1,13}=2.48, P=0.1330$ ); full tables are in Appendix B. (B) Leaf toughness (ANOVA: region, $F_{1,13}=34.95, P$ $<0.0001$ ). (C) Trichome number on the abaxial (underneath) surface of mature $C$. maculosa leaves (ANOVA: region, $F_{1,18}=8.42$, $P=0.0084$; population, $F_{18,79}=2.81, P=0.0009$ ). (D) Leaf nitrogen concentration in mature $C$. maculosa leaves (ANOVA: region, $\left.F_{1,18}=6.21, P=0.0214\right)$.

$0.1002)$ in this direction for $( \pm)$-catechin. Zhang and Jiang (2006) argued that if the invasive range is more nutrient-poor than the native range there could be selection for increased plant defense even if exotics experience enemy release.

\section{Ploidy}

The higher performance of North American populations in our experiments could be due to differences in ploidy. Centaurea maculosa populations can be either diploid or tetraploid (Müller 1989), and North American populations appear to be almost exclusively tetraploid whereas in Europe both tetraploid and diploid populations are common (H. Müller-Schärer, personal communication). However, in one experiment we found that North American tetraploids were larger than European tetraploids, suggesting that ploidy is not the reason North American plants are larger. An earlier comparison found that plants from a diploid population in Hungary were larger than plants from a tetraploid population in North America (Müller 1989).

\section{Generalists vs. specialists}

EICA makes predictions about specialist herbivores, not generalists. Müller-Schärer et al. (2004) proposed that the most important change in herbivory experienced by introduced plant species is a "shift in the composition in the enemy complex towards an assemblage dominated by generalists." Based on this perspective they reasoned that the evolution of increased competitive ability documented for many invasive species "is best explained by a reallocation of resources from costly quantitative defenses to growth," because quantitative defense compounds deter herbivory by both specialist and generalist herbivores. Importantly, they also argue that qualitative defenses that are toxic to generalist herbivores may actually increase in the invaded range, as we found for C. maculosa. Thus, they predict that some invasive species might be able to evolve increased resistance to generalist herbivores without cost, as qualitative plant defense compounds effective at deterring generalists would confer an advantage in an environment containing generalists but lacking specialists.

Our case for Centaurea appears to be similar to the idea proposed by Müller-Schärer et al. (2004). We found that both specialist and generalist herbivores demonstrated superior performance on plants from native European Centaurea populations, but specialist insects showed a weaker response. Almost all metrics for the 

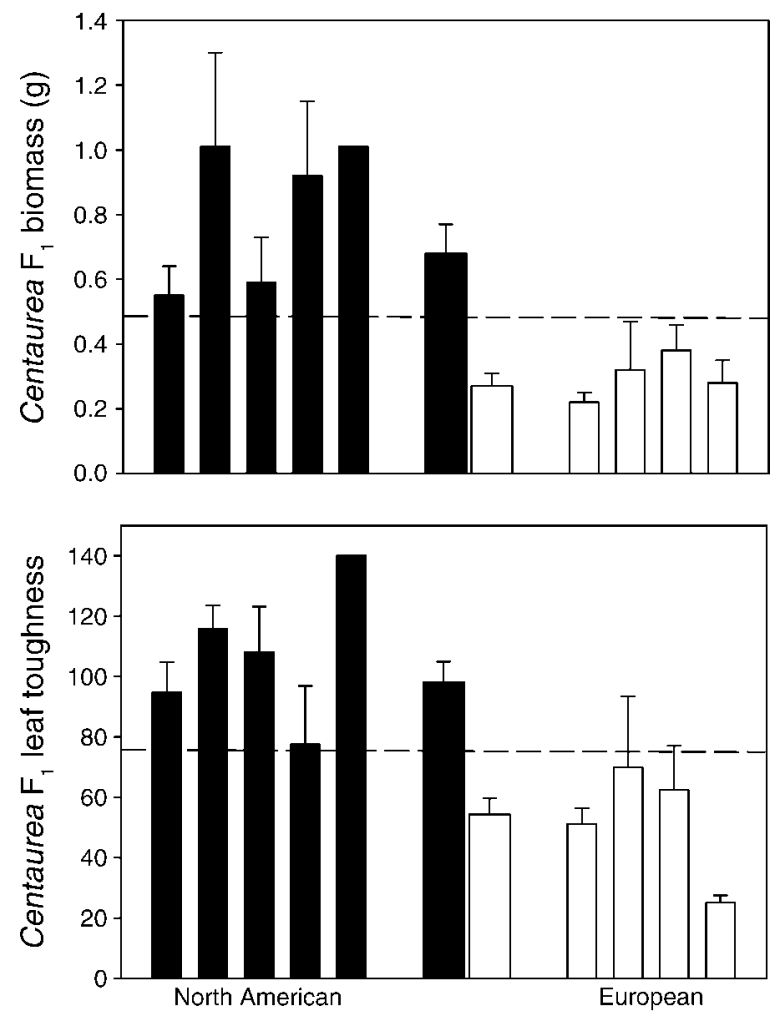

FIG. 9. Biomass and leaf "toughness" for the $F_{1}$ generations of plants from North American and European populations of Centaurea maculosa. All hand-pollination crosses were made within populations. Thinner bars represent means and SE for individual populations; thicker bars in the center represent means and SE for the two regions. ANOVA for biomass (Appendix B): region, $F_{1,7}=13.01, P=0.0045$. ANOVA for leaf toughness: region, $F_{1,7}=8.96, P=0.0171$. Toughness was measured in units of grams by a penetrometer.

two generalists showed strong and highly significant regional differences. Similarly, Joshi and Vrieling (2005) found that invasive populations of Senecio jacobaea, a noxious invasive weed worldwide, demonstrated higher biomass, but that pyrrolizidine alkaloids, primary antigeneralist herbivore compounds, were also higher in invasive populations. However, they observed that this shift resulted in lower protection against specialists.

\section{Conclusions}

Strong directional selection can work rapidly; Thompson (1998, also see 2005) argued that "interspecific interactions have now been shown to coevolve over the timescale of decades." Others have reported rapid evolution in natural populations (Reznick et al. 1997, Siemann and Rogers 2001, 2003) and our results suggest that the new plant and generalist herbivore neighbors encountered by Centaurea maculosa in its invaded range may exert strong directional selection on this invader's defensive and allelopathic biochemistry. If this is so, the disruption of such evolutionary relationships (see Cal- laway and Ridenour 2004, Hallett 2006) may explain why some plant species are such successful invaders.

\section{ACKNOWLEDGMENTS}

Work performed in the Vivanco lab was funded by the National Science Foundation (IBN 0335203) and the U.S. Department of Defense SERDP (CS1388). Jun-ichiro Horiuchi acknowledges the financial support from Japan Society for the Promotion of Science. R. M. Callaway and W. M. Ridenour were funded by the Aldo Leopold Wilderness Center, the USFS Fire Sciences Laboratory, the USDA, DoD SERDP, the National Science Foundation, and the Civilian Research and Development Foundation.

\section{Literature Cited}

Agrawal, A. A., and M. Fishbein. 2006. Plant defense syndromes. Ecology 87:S142-S149.

Agrawal, A. A., and R. Karban. 1999. Why induced defenses may be favored over constitutive strategies in plants. Pages 45-61 in R. Tollrian and C. D. Harvell, editors. The ecology and evolution of inducible defenses. Princeton University Press, Princeton, New Jersey, USA.

Agren, J., and D. W. Schemske. 1992. Artificial selection on trichome number in Brassica rapa. Theoretical Applied Genetics 83:673-678.

Arimura, G., R. Ozawa, T. Shimoda, T. Nishioka, W. Boland, and J. Takabayashi. 2000. Herbivory-induced volatiles elicit defence genes in lima bean leaves. Nature 406:512-515.

Bais, H. P., R. Vepachedu, S. Gilroy, R. M. Callaway, and J. M. Vivanco. 2003. Allelopathy and exotic plant invasion: from molecules and genes to interactions. Science 301:13771380.

Blair, A. C., B. D. Hanson, G. R. Brunk, R. A. Marrs, P. Westra, S. J. Nissen, and R. A. Hufbauer. 2005. New techniques and findings in the study of a candidate allelochemical implicated in invasion success. Ecology Letters 8:1039-1047.

Blair, A. C., S. J. Nissen, G. R. Brunk, and R. A. Hufbauer. 2006. A lack of evidence for an ecological role of the putative allelochemical $( \pm)$-catechin in spotted knapweed invasion success. Journal of Chemical Ecology 32:2327-2331.

Blossey, B., and R. Nötzold. 1995. Evolution of increased competitive ability in invasive non-indigenous plants: a hypothesis. Journal of Ecology 83:887-889.

Bossdorf, O., H. Auge, L. Lafuma, W. E. Rogers, E. Siemann, and D. Prati. 2005. Phenotypic and genetic differentiation between native and introduced populations. Oecologia 144: $1-11$.

Bossdorf, O., D. Prati, H. Auge, and B. Schmid. 2004. Reduced competitive ability in an invasive plant. Ecology Letters 7: 346-353.

Buta, J. G., and W. R. Lusby. 1986. Catechins as germination and growth inhibitors in lespedeza seeds. Phytochemistry 25: 93-95.

Callaway, R. M., and E. T. Aschehoug. 2000. Invasive plants versus their new and old neighbors: a mechanism for exotic invasion. Science 290:521-523.

Callaway, R. M., D. Cipollini, K. Barto, G. C. Thelen, S. G. Hallett, D. Prati, K. Stinson, and J. Klironomos. 2008. Novel weapons: invasive plant suppresses fungal mutualists in America but not in its native Europe. Ecology 89:1043-1055.

Callaway, R. M., T. DeLuca, and W. M. Ridenour. 1999. Herbivores used for biological control may increase the competitive ability of the noxious weed Centaurea maculosa. Ecology 80:1196-1201.

Callaway, R. M., J. L. Hierro, and A. S. Thorpe. 2005. Evolutionary trajectories in plant and soil microbial communities: Centaurea invasions and the geographic mosaic of coevolution. Pages 341-363 in D. F. Sax, S. D. Gaines, and J. J. Stachowicz, editors. Exotic species invasions: insights 
into ecology, evolution and biogeography. Sinauer, Sunderland, Massachusetts, USA.

Callaway, R. M., and W. M. Ridenour. 2004. Novel weapons: a biochemically based hypothesis for invasive success and the evolution of increased competitive ability. Frontiers in Ecology and the Environment 2:436-433.

Callaway, R. M., G. T. Thelen, S. Barth, W. Ramsey, and J. E. Gannon. 2004. Soil fungi alter interactions between the invader Centaurea maculosa and North American natives. Ecology 85:1062-1071.

Cappuccino, N., and J. T. Arnason. 2006. Novel chemistry of invasive exotic plants. Biology Letters 2:189-193.

Cappuccino, N., and D. Carpenter. 2005. Invasive exotic plants suffer less herbivory than non-invasive plants. Biology Letters 1:435-438.

Carpenter, D., and N. Cappuccino. 2005. Herbivory, time since introduction and the invasiveness of exotic plants. Journal of Ecology 93:315-321.

Coley, P. D. 1983. Herbivory and defensive characteristics of tree species in a lowland tropical forest. Ecological Monographs 53:209-234.

D’Abrosca, B., M. Dellagreca, A. Fiorention, M. Isidori, P. Monaco, and S. Pacifico. 2006. Chemical constituents of the aquatic plant Schoenoplectus lacustris: evaluation of phytotoxic effects on the green alga Selenatrum capricornutum. Journal of Chemical Ecology 32:81-96.

Grime, J. P. 1977. Evidence for the existence of three primary strategies in plants and its relevance to ecological and evolutionary theory. American Naturalist 111:1169-1194.

Hallett, S. G. 2006. Dislocation from coevolved relationships: a unifying theory for plant invasion and naturalization? Weed Science 54:282-290.

Herms, D. A., and W. J. Mattson. 1992. The dilemma of plants: to grow or defend. Quarterly Review of Biology 67:283-335.

Inderjit, T., R. Seastedt, R. M. Callaway, J. L. Pollock, and J. Kaur. In press. Allelopathy and plant invasions: traditional, congeneric, and biogeographical approaches. Biological Invasions.

Iqbal, Z., S. Hiradate, A. Noda, S. I. Isojima, and Y. Fujii. 2003. Allelopathic activity of buckwheat: isolation and characterization of phenolics. Weed Science 51:657-662.

Janzen, D. H. 1975. Pseudomyrmex nigripilosa: a parasite of a mutualism. Science 188:936-937.

Joshi, J., and K. Vrieling. 2005. The enemy release and EICA hypothesis revisited: incorporating the difference between specialist and generalist herbivores. Ecology Letters 8:704714.

Leger, E. A., and K. J. Rice. 2003. Invasive Californian poppies (Eschscholzia californica Cham.) grow larger than native individuals under reduced competition. Ecology Letters 6: 257-264.

Lesica, P., and J. S. Shelley. 1996. Competitive effects of Centaurea maculosa on the population dynamics of Arabis fecundis. Bulletin Torrey Botanical Club 123:111-121.

Mallik, A. U., and F. Pellissier. 2000. Effects of Vaccinium myrtillus on spruce regeneration: testing the notion of coevolutionary significance of allelopathy. Journal of Chemical Ecology 26:2197-2209.

Maron, J. L., and M. Vilà. 2001. When do herbivores affect plant invasion? Evidence for the natural enemies and biotic resistance hypotheses. Oikos 95:361-373.

Maron, J. L., M. Vilà, R. Bommarco, S. Elmendorf, and P. Beardsley. 2004. Rapid evolution of an invasive plant. Ecological Monographs 74:261-280.

McKey, D. 1974. Adaptive patterns in alkaloid physiology. American Naturalist 108:305-320.

Müller, H. 1989. Growth pattern of diploid and tetraploid spotted knapweed, Centaurea maculosa Lam. (Compositae), and effects of the root-mining moth Agapeta. Weed Research 29:103-111.
Müller-Schärer, H., U. Schaffner, and T. Steinger. 2004. Evolution in invasive plants: implications for biological control. Trends in Ecology and Evolution 19:417-422.

Murashige, T., and F. Skoog. 1962. A revised medium for rapid growth and bioassay with tissue culture. Physiologia Planta 15:473-497.

Olson, B. E., and R. G. Kelsey. 1997. Effect of Centaurea maculosa on sheep rumen microbial activity and mass in vitro. Journal of Chemical Ecology 23:1131-1144.

Perry, L. G., C. Johnson, E. R. Alford, J. M. Vivanco, and M. W. Paschke. 2005a. Screening of grassland plants for restoration after spotted knapweed invasion. Restoration Ecology 13:725-735.

Perry, L. G., G. C. Thelen, W. M. Ridenour, R. M. Callaway, M. W. Paschke, and J. M. Vivanco. In press. Soil concentrations of the allelochemical $( \pm)$-catechin. Journal of Chemical Ecology.

Perry, L. G., G. C. Thelen, W. M. Ridenour, T. L. Weir, R. M. Callaway, M. W. Paschke, and J. M. Vivanco. 2005b. Dual role for an allelochemical: ( \pm )-catechin from Centaurea maculosa root exudates regulates conspecific seedling establishment. Journal of Ecology 93:1126-1135.

Rabotnov, T. A. 1982. Importance of the evolutionary approach to the study of allelopathy. Ékologia 3(MayJune):5-8. [Translated from Russian.]

Reznick, D. N., and C. K. Ghalambor. 2001. The population ecology of contemporary adaptations: what empirical studies reveal about the conditions that promote adaptive evolution. Genetica 112-113:183-198.

Reznick, D. N., F. H. Shaw, F. H. Rodd, and R. G. Shaw. 1997. Evaluation of the rate of evolution in natural populations of guppies (Poecilia reticulata). Science 275: 1934-1937.

Ridenour, W. M., and R. M. Callaway. 2001. The relative importance of allelopathy in interference: the effects of an invasive weed on a native bunchgrass. Oecologia 126:444 450 .

Rossiter, M. C. 1996. Incidence and consequences of inherited environmental effects. Annual Review of Ecology and Systematics 27:451-476.

Schierenbeck, K. N., R. N. Mack, and R. R. Sharitz. 1994. Effects of herbivory on growth and biomass allocation in native and introduced species of Lonicera. Ecology 75:16611672.

Siemann, E., and W. E. Rogers. 2001. Genetic differences in growth of an invasive tree species. Ecology Letters 4:514-518.

Siemann, E., and W. E. Rogers. 2003. Reduced resistance of invasive varieties of the alien tree Sapium sebiferum to a generalist herbivore. Oecologia 135:451-457.

Siemens, D., S. Garner, T. Mitchell-Olds, and R. M. Callaway. 2002. Cost of defense in the context of competition: Brassica rapa may grow and defend. Ecology 83:505-517.

Simões, K., J. Du, F. S. Kretzshmar, C. D. Broeckling, F. S. Stermiz, J. M. Vivanco, and M. R. Braga. In press. Phytotoxic compounds exuded by seeds of the tropical weed Sesbania virgata. Journal of Chemical Ecology.

Story, J. M., W. R. Good, L. J. White, and L. Smith. 2000. Effects of the interaction of the biocontrol agent Agapeta zoegana (L.) (Lepidoptera: Cochylidae) and grass competition on spotted knapweed. Biological Control 17:182-190.

Strauss, S. Y., and A. A. Agrawal. 1999. The ecology and evolution of plant tolerance to herbivory. Trends in Ecology and Evolution 14:179-185.

Thelen, G. C., J. M. Vivanco, B. Newingham, W. Good, H. P. Bais, P. Landres, A. Caesar, and R. M. Callaway. 2005. Insect herbivory stimulates allelopathic exudation by an invasive plant and the suppression of natives. Ecology Letters 8:209-217.

Thompson, J. N. 1998. Rapid evolution as an ecological process. Trends in Ecology and Evolution 13:329-331. 
Thompson, J. N. 2005. The geographic mosaic theory of coevolution. University of Chicago Press, Chicago, Illinois, USA.

Thorpe, A. S. 2006. Biochemical effects of Centaurea maculosa on soil nutrient cycles and plant communities. Dissertation. The University of Montana, Missoula, Montana, USA.

Vilá, M., A. Gómez, and J. L. Maron. 2003. Are alien plants more competitive than their native conspecifics? A test using Hypericum perforatum L. Oecologia 137:211-215.

Vilá, M., and J. Weiner. 2004. Are invasive plant species better competitors than native plant species? Evidence from pairwise experiments. Oikos 105:229-238.

Vivanco, J. M., H. P. Bais, F. R. Stermitz, G. C. Thelen, and R. M. Callaway. 2004. Biogeographical variation in community response to root allelochemistry: novel weapons and exotic invasion. Ecology Letters 7:285-292.

Weir, T. L., H. P. Bais, V. J. Stull, R. M. Callaway, G. C. Thelen, W. M. Ridenour, S. Bhamidi, F. R. Stermitz, and J. M. Vivanco. 2006. Oxalate contributes to the resistance of
Gaillardia grandiflora and Lupinus sericeus to a phytotoxin produced by Centaurea maculosa. Planta 223:785-795.

Weir, T. L., H. P. Bais, and J. M. Vivanco. 2003. Intraspecific and interspecific interactions mediated by a phytotoxin, (-)catechin, secreted by the roots of Centaurea maculosa (spotted knapweed). Journal of Chemical Ecology 29:2379 2393.

Willis, A. J., M. B. Thomas, and J. H. Lawton. 1999. Is the increased vigour of invasive weeds explained by a trade-off between growth and herbivore resistance? Oecologia 120: 632-640.

Wolfe, L. M., J. A. Elzinga, and A. Biere. 2004. Increased susceptibility to enemies following introduction in the invasive plant Silene latifolia. Ecology Letters 7:813-820.

Zhang, D., and X. Jiang. 2006. Interactive effects of habitat productivity and herbivore pressure on the evolution of antiherbivore defense in invasive plant populations. Journal of Theoretical Biology 232:935-940.

\section{APPENDIX A}

Populations used in growth and herbivory experiments (Ecological Archives M078-014-A1).

\section{APPENDIX B}

ANOVA tables for growth, herbivory, palatability, $( \pm$ )-catechin, and maternal effects experiments (Ecological Archives M078014-A2).

\section{APPENDIX C}

Germination rates (percentage) for North American and European populations of Centaurea maculosa (Ecological Archives M078-014-A3).

\section{APPENDIX D}

Mean total biomass of Centaurea maculosa from European and North American populations: (A) with and without Agapeta zoegana infecting roots and (B) at the end of the experiment with Cyphocleonus achates; controls, and treatment combined (Ecological Archives M078-014-A4). 